\title{
TEMAS PRINCIPALES EN LA ESCULTURA HUASTECA
}

\section{Beatriz de la Fuente}

El interés que despertó la cultura huasteca desde fines del siglo pasado, como lo muestran los reportes de Seler, y que se continuó ya en este siglo con otros reportes y estudios de Fewkes, Velázquez, Blas Rodríguez, Staub, Du Solier, Ekholm, Mac Neish, García Payón, Medellín, Stresser-Péan y en especial de Joaquín Meade, quien dedicó su vida al rescate de la cultura huasteca prehispánica, parece haber disminuido recientemente.

En lo que corresponde a las esculturas en particular, las referencias que de ellas se hacen en estudios acerca de Mesoamérica, se limitan a unas cuantas. Tan sólo una tesis doctoral, no publicada, y accesible a un número reducido de interesados, versa sobre el tema

El primer paso para poder iniciar cualquier estudio riguroso de la estatuaria huasteca es tener un panorama general de la misma. No se pueden establecer normas de forma, de estilo o de iconografía artística, si para ello se tienen como base unas cuantas obras de arte. Menos aún me parece que, con haber visto esas cuantas obras y haber leido planteamientos superficiales acerca de su significado, se propongan, sin cuestionarse, teorias de carácter cultural y socio-económico.

Debido a la dispersión de las tallas que se encuentran en Museos y Colecciones de la República Mexicana y de otros paises, y porque no toda la zona huasteca ha sido explorada arqueológicamente, el panorama que se pretende no puede ser exhaustivo. He podido registrar, sin embargo, 436 esculturas completas o fragmentadas. Resultado evidente de la investigación realizada para dicho registro, es el poder establecer conjuntos homogéneos tomando en cuenta los temas que en las esculturas se representan. No pretendo, por aho$\mathrm{ra}$, sino presentar de manera consecuente lo que éstas comunican en cuanto a los asuntos reiteradamente figurados en ellas; dejo fuera aspectos de interpretación y posible significación simbólica y cultural

Se ha aceptado que la cultura huasteca es aquella que se desarrolló en la costa del Golfo, en el noreste de la actual República Mexicana, incluyendo la parte sur del estado de Tamaulipas, el norte de Veracruz, el este de San Luis Potosi, y porciones de Querétaro, Hidalgo y Puebla. Las fronteras de esta región geográfico-cultural han sido variables con el tiempo; en ella se asentaron, desde el primer milenio a. de $\mathrm{C}$, los huastecas, grupo humano que compartía raza y lengua.

Es bien conocido que tal cultura no se mantuvo aislada en su trayectoria y que se vio alterada por la influencia o la presencia misma de otros pueblos de Mesoamérica Estudios sobre lingüística, antropología física, y cerámica, apuntan en la dirección de que huastecas y mayas eran una misma raza que habitó la costa del Golfo hasta antes de los años 1500 a 100 a de C.; después de esta época se vieron separados por causas que no quedan aún claras, y los 
huastecas se restringieron a la región antes mencionada, en tanto que los mayas se fueron a poblar el sureste de Mesoamérica "La cerámica de la Huasteca revela, en su época más antigua, contactos con Oaxaca y con la zona maya; con Teotihuacan y con Tajín, durante el periodo clásico, y con las cerámicas tolteca y azteca durante el periodo posclásico. Es a fines del clásico y sobre todo durante el posclásico temprano, cuando aparece en la región una cerámica característica, propia y diferente a otras de Mesoamérica. Los sistemas de fechamiento distan aún de ser precisos y se basan todavía en los estudios sobre características y cambios en la cerámica propuestos para Tampico y Pánuco por Ekholm (1944) y para Pánuco por Mac Neish (1954). Estos han sido adaptados a un marco de referencia general de las cronologías de Mesoamérica por Piña Chán (1967) y por García Payón (1976).

No es posible fechar con certeza las esculturas huastecas. Quizá la mayor parte fueron ejecutadas a lo largo de dos o cuando más de tres siglos, en el posclásico temprano, siglos X a XII. Diseños que aparecen en los recipientes de barro, a saber: la doble voluta en forma de $S$ horizontal, formas oblongas hexagonales y octogonales con puntos en hilada en su interior, circulos con puntos concéntricos y cruces con los brazos en forma de I, se encuentran también en las esculturas de piedra. Por otra parte, algunas de las vasijas antropomorfas son muy semejantes a las tallas pétreas, como por ejemplo la que representa a un jorobado en el Museo Nacional de Antropología de México, muestra las mismas soluciones formales que las estatuas de piedra de jorobados, en el mismo Museo o en el Museo Regional Potosino. Además, ciertas vasijas de forma humana llevan una marca en el rostro, una línea que parte de la comisura externa del ojo y que se prolonga en diagonal a la parte inferior de la oreja del mismo lado; marca semejante, figurada como un reborde, se ve en los rostros de esculturas como "El Adolescente" de El Consuelo y en la figura masculina de "La Apoteosis" de Tancuayalab Estas semejanzas de carácter formal, temático y simbólico entre piezas de cerámica y de piedra, sugieren posible contemporaneidad. Un mismo lenguaje àrtístico se mauifiesta a través de distinto material en objetos que, acaso, tuvieran similar destino.

La primera división de la escultura huasteca para constituir conjuntos homogéneos, responde a un criterio que se apoya aparentemente en aspectos técnicos. El primer grupo considerablemente numeroso, está formado por esculturas; el segundo, por una escasa suma de relieves. En realidad establezco estos dos conjuntos porque los asuntos representados en esculturas difieren de aquellos figurados en relieves. La gran mayoria de las primeras, si se exceptúan las que llevan otra figura a cuestas, son representaciones de figuras únicas, en tanto que en los segundos se prefiere mostrar escenas en que participan varias imágenes.

\section{Escultura}

Se entiende por ella el volumen que ocupa un lugar en el espacio. Las piezas con estas características pueden agruparse en seis categorias de acuerdo 
con sus rasgos visibles más relevantes: Figuras humanas femeninas, Figuras humanas masculinas; Figuras humanas cuyo sexo no es determinable, Figuras de animales, Figuras mixtas y las que no caben dentro de los grupos anteriores.

\subsection{Figuras humanas femeninas}

Constituyen un conjunto que oscila desde las figuras simples, toscamente ejecutadas, hasta las otras cuidadosamente labradas que usan vistosos tocados a veces decorados con diseños en relieve. Las más sencillas se caracterizan porque muestran el cuerpo desnudo y carecen de tocado o lo llevan sumamente discreto; las más complejas usan, además de un gran tocado, falda que cubre su cuerpo desde la cintura hasta media pierna o hasta los pies.

Las soluciones formales de este conjunto son, sin embargo, similares y contribuyen a darle unidad (lám. 1). Las figuras son representadas de pie, sobre una pequeña base que se continúa con una espiga; están perfectamente erguidas, con el cuerpo y la cabeza colocados de frente. Las piernas van ligeramente separadas entre sí, y los brazos bajan a los lados del cuerpo en tanto que las manos se apoyan sobre el vientre. Si se traza virtualmente un eje vertical que divida la figura por la mitad, se verá que los dos lados tienen total correspondencia; la simetria axial y la posición de la figura les confieren rigidez. Por otra parte el corte de la piedra, en la típica losa arenisca de poco espesor, puede producir contornos rectos y angulosos, de manera que la figura, si se la mira de frente, puede quedar dentro de un rectángulo, o curvos en forma tal que la figura queda inscrita en su parte inferior en un rectángulo y en la superior en un semicírculo.

El mayor interés escultórico se encuentra al frente de las figuras; la vista posterior, excepción hecha del tocado, es comunmente lisa. Por lo general son bloques compactos aunque ligeros, debido al poco grosor de la losa en que se labraron; en algunas se acentúa la ligereza cuando los brazos se desprenden del torso, permitiendo que el espacio corte el volumen.

Los rostros de estas figuras se ven casi siempre inertes y sin expresión; son formas estereotipadas que responden al esquema establecido. Rostros de forma ovoide, con arcos superciliares bien marcados; ojos como abultamientos o como huecos ovales sin iris señalados; boca de labios cerrados, y grandes orejas que se miran despegadas de la cabeza y al frente del tocado.

1.1. Las figuras más simples y pobremente talladas están por lo general mostrando los pechos y el órgano sexual; por no llevar tocado, permiten que se aprecie en algunas la deformación craneal (lám. 2). En otras el tocado es como una banda que circunda el rostro y que puede ser alto o bajar sobre la espalda

1.1.2 Las figuras más complejas llevan medio cuerpo cubierto por una falda de largo variable, plana, de perfiles rectos y de superficie lisa. El torso va siempre desnudo mostrando los pechos; éstos se ven, a veces, limitados en su 
parte inferior con rebordes que parecen simular pliegues de carne (lám. 3). El elemento distintivo es el tocado, cuya importancia escultórica sugiere que es la parte que otorga prestigio a la figura.

Los tocados se componen de varios elementos, uno de los cuales es constante: se trata de una superficie plana en forma de abanico, que de aquí en adelante designaré simplemente como abanico, y en la cual se apoyan otros elementos que pueden ser variables. Por el aspecto de estos elementos se aprecian: a) tocados que tienen una banda o bloque rectangular, un elemento o gorro cónico y un elemento en forma de abanico y b) tocados zoomorfos que llevan, sobre el abanico, una representación animal.

a) Algunos de estos tocados llevan decoración en relieve con diseños característicamente huastecas (lám. 4). Al frente, en el abanico, se presentan dos ti- pos de diseños paralelos que siguen la curvatura del tocado. El diseño exterior se compone de círculos con un disco central; el exterior está formado por discos resaltados colocados en la orilla y enmarcados por una banda ondulante. En la parte inferior del mismo abanico se ven, de perfil, cabezas de serpiente con las fauces abiertas. En otras esculturas se aprecian, también en el abani$\mathrm{co}$, ranuraciones onduladas y radiales que lo hacen simular un penacho de papel plegado y que a veces se representan también en su vista posterior (lám. 6). Hay otras variantes del tocado en las cuales, en lugar del bloque y del elemento cónico, se representan formas rectangulares o trapezoidales que se prolongan hacia arriba y alcanzan o superan la altura del abanico (lám 5).

b) Las figuras con tocado zoomorfo y abanico se distinguen porque el rostro se encuentra enmarcado por el pico abierto de un ave o por las fauces de una serpiente (lám. 7). En alguna se combinan las dos especies; el pico o las fauces se proyectan hacia afuera, en tanto que los ojos como abultamientos ovales se adhieren a la superficie del abanico

\subsection{Figuras humanas masculinas}

Constituyen un conjunto numeroso, variado y que muestra distintas soluciones formales. Como en el de las figuras femeninas, se encuentran desde las representaciones más esquemáticas en las cuales el cuerpo está desnudo y la cabeza carece de tocado o si lo lleva es a manera de gorro o banda ceñida o realzada, hasta las figuraciones en las cuales el tocado, el vestuario y los adornos adquieren definitiva importancia. La presencia del abanico no es constante en el tocado; en cambio, predominan en él las formas cónicas, y son muy pocos los que se conocen con apariencia de fauces abiertas de las cuales emerge el rostro. Además de estas modalidades, hay también otros grupos que tienen el mismo tema de representación. Se trata de figuras de jorobados, de figuras que toman una barra entre las manos, y de figuras que llevan otra a cuestas. Cada uno de estos grupos exhibe rasgos constantes y otros que son variables.

Por otra parte, además de la diversidad temática de las figuras masculinas, hay en éstas, dentro de los cánones del estilo, mayor variedad formal que en 
las femeninas. Muchas de las figuras desnudas y sin tocado o con tocado simple, y todas las figuras vestidas y con vistosos tocados, están talladas en una losa de manera que el ancho de ésta es el frente de la figura; tienen, por lo tanto, poco espesor y son estáticas; en cambio, los jorobados y las que sostienen una barra están labrados de modo que la parte estrecha de la losa viene a ser el frente de la figura; éstas llevan las piernas dobladas, y un espacio las penetra entre los brazos, el cuerpo, las piernas y la barra que sostienen; el dinamismo plástico es visible.

1.21 Las figuras masculinas desnudas, sin tocado o con tocado ceñido a la cabeza, de pequeñas dimensiones, se apoyan en una plataforma y se continúan hacia abajo en una espiga (lám. 8). Su contorno general puede quedar inscrito en un estrecho rectángulo que se alarga en sentido vertical y que se apunta hacia arriba. En su conjunto son formas estáticas y cerradas, de rasgos sintetizados, brazos pegados al cuerpo y piernas unidas entre sí

Dentro de esta categoría considero que deben quedar incluidas otras esculturas masculinas que llevan tocado sencillo ceñido a la cabeza, dejando ver la acentuada deformación craneal, y que usan máxtlatl con paños colgantes decorados; llevan en parte del cuerpo, del tocado o del máxtlatl, diseños simbólicos que les confier en una dimensión diferente a la de las figuras desnudas (lám.9). Además de su atuendo, las distinguen la delicadeza de la talla y la finura en el acabado; son también más esbeltas en su estructura; los brazos se desprenden del cuerpo y se dirigen hacia afuera y un espacio penetra entre las piernas

1.2.2 Entre las figuras con tocados elaborados y con vestuario, las hay pequeñas y grandes; son más abundantes éstas y su grado de complejidad en las formas y en los diseños de las prendas de vestir y de los ornamentos de la cabeza es también mayor. Todas están de pie, miran hacia el frente y pueden constituir un volumen sólido o estar traspasadas por espacios entre los brazos, el cuerpo y las piernas; son formas estáticas en las cuales lo único que quiebra la simetría bilateral son los brazos; es frecuente que uno de ellos se doble en ángulo recto y apoye la mano sobre el vientre, en tanto que el otro se recoge en ángulo obtuso y coloca la mano sobre el pecho. Usan, por lo general, máxtlatl con paños colgantes, gran pectoral de contornos curvos en la parte superior y forma trapezoidal en la inferior, que puede ir ahuecado por una horadación circular, y orejeras circulares que se prolongan en ganchos curvados hacia afuera (lám. 10)

En esta categoría se incluyen: a) las que usan tocado cónico, b) las que llevan tocado en forma de abanico $\mathrm{y}, \mathrm{c}$ ) las que muestran en el tocado además del abanico una máscara antropomorfa y, d) las de tocado zoomorfo

a) Las figuras que tienen tocado cónico, que siempre se levanta sobre una banda que circunda la cabeza, son de estructura simple: sobre un prisma rectangular se apoya una forma cónica (lám. 11). Las figuras pequeñas suelen carecer de adornos, mientras que en las de mayor tamaño el vestuario se enriquece con delantales, faldas y ceñidores y elementos simbólicos en pectorales, tocados y ornamentos (lám. 12). 
b) De las figuras masculinas con tocado en forma de abanico, sólo una mantiene los mismos elementos que las esculturas femeninas: se trata de la que está en Los Angeles County, Natural History Museum. Otras dos con tocado de abanico llevan al frente un gorro curvo y abombado del que se desprende un elemento trapezoidal (lám. 13)

c) Un grupo particular de las figuras masculinas, es el de las esculturas que llevan tocados de abanico, en cuyo frente está representada una máscara antropomorfa con arrugas; de su boca abierta sale el rostro (lám. 14).

d) Son pocas y muy destruidas las esculturas masculinas con tocados zoomorfos; todos éstos son cabezas de ave de cuyo pico abierto emerge el rostro humano

1.2.3 Figuras masculinas jorobadas Considero aquí a las figuras que exhiben protuberancias anormales en la espalda y en el pecho; es ésta su principal característica. Algunas son ciertamente estrechas, otras tienen medidas más amplias. Varias de ellas muestran jorobas en la espalda y en el pecho; su postura típica es sentadas sobre sus talones con las rodillas apoyadas en el suelo. Llevan por tocado una o varias bandas alrededor de la cabeza, y su cuerpo se ve sólo cubierto por un taparrabo (lám. 15). Son de entre las esculturas huastecas, las que más se apegan al dato natural y las que muestran, por lo tanto, mayor individualidad.

1.2.4 Categoría única en el arte de Mesoamérica es la del conjunto -30 piezas - de figuras masculinas que toman una barra cilíndrica entre sus manos. Rasgo distintivo éste que le da unidad al conjunto y atributo que indica el significado y la función ritual de las figuras (lám. 16)

Algunas son a la vez figuras de jorobados y de viejos, aunque estos rasgos no son exclusivos del conjunto (lám. 17). Lo que le da unidad es que todas se encuentran de pie sobre una plataforma, con las rodillas ligeramente dobladas, el cuerpo echado hacia adelante y los brazos extendidos hacia el frente tomando la barra entre sus manos. Casi todas llevan máxtlatl y van sin tocado, o si lo usan es como un gorro ceñido a la cabeza; a menudo se ven perforadas por un espacio de forma irregular entre la plataforma, las piernas, el cuerpo, los brazos y la barra, pero hay otras que constituyen un volumen cerrado, y la figura aparece como montada sobre el bloque de piedra Quiero hacer mención de una escultura particular que se encuentra en el Musée de l'Homme de París; en lo general participa de las características propias a este conjunto, pero se distancía de él porque lleva una figura menor a cuestas; comparte así un rasgo en que me he apoyado para establecer otro conjunto temático (lám. 18).

1.2.5 Asuntos diferentes de los anteriores son los representados en las esculturas en que se muestran dos figuras. Con frecuencia, una figura masculina mayor lleva sobre su espalda a otra con aspecto infantil (lám. 19), que se ve como montada sobre la primera; hay otras que lo que llevan a cuestas es un esqueleto (lám. 20). Hay otras variaciones en esculturas que se encuentran en malas condiciones. 
En este conjunto se encuentran algunas de las figuras más finamente acabadas, y que muestran en su ornamentación corporal a base de finos diseños en relieve, en sus atributos del tocado y en sus rasgos formales y de representación, los elementos propios a las convenciones escultóricas huastecas.

13 He agrupado algunas esculturas bajo el título de Figuras humanas cuyo sexo no es determinable; no presentan, como en los conjuntos anteriores, elementos que permitan precisar la índole de aquél (lám 21). Incluyo aquí a la figura humana con rostro descarnado que se encuentra en el Museo Nacional de Antropología (lám. 22).

1.4 Pocas son las esculturas en tres dimensiones que representan animales; algunas parecen tener cuerpo humano y cabeza zoomorfa. Entre las primeras destacan un mono sedente que procede de Tanquián y que está en las Bodegas del Museo Nacional de Antropología, un chapulin recientemente encontrado en San Luis Potosí, y un águila, posiblemente un cuauhxicalli, del Museo de Tampico Alto, Veracruz.

Las que restan, 5 en total, no son identificables ya que mezclan rasgos de distinto género. En relieve hay también representaciones de animales fantásticos.

1.5 Algunas piezas no ocupan lugar en los conjuntos antes establecidos, porque son piezas únicas que en lo formal no siguen los esquemas establecidos. Me refiero al recipiente de piedra con dos serpientes a su alrededor del Museo de Brooklyn, al gran falo de las Bodegas del Museo Nacional de Antropología y al disco con diseños ciertamente huastecas y que se supone lieva una fecha del Tonalpohualli (lám. 23)

\section{Relieve.}

Los escultores huastecas trabajaron a lo ancho de las losas arenisca unas veinte en relieve, además de tres que fueron incisas.

Es interesante que los asuntos representados en relieve difieran sustancialmente de los que se encuentran en la escultura tridimensional. Por una parte, la técnica en sí propicia el desarrollo escénico y la figuración completa y en actividad de las figuras; pero, además, el labrado cuidadoso y pormenorizado de los detalles del atavio, del tocado, de los diseños corporales y del vestuario, convierte los relieves en piezas excepcionales e inconfundibles. Hay en ellas algunas representaciones de carácter naturalista; pero, en lo general, la manera de figurar es estilizada y fantástica y el lenguaje artístico se vuelve más complejo y esotérico

Considero que hay por lo menos tres grandes temas tratados en los relieves actualmente conocidos: a) El primero consiste en representaciones de figuras humanas, pero mostradas en su condición sobrenatural. Esta condición se la imprimen las garras en lugar de manos y el rostro irreal y descarnado, o las máscaras que transforman la fisonomía del hombre y lo convierten en ser inexistente en la naturaleza (lám. 24); b) el segundo de los temas se repite en 
tres losas, dos completas y una fragmentada; se trata de escenas de autosacrificio que se llevan a cabo en un marco de formas simbólicas y figuras fantásticas (lám. 25); c) el tercer tema significativo es el de las representaciones estilizadas de aves, posiblemente águilas, vistas de perfil en la parte superior de las losas (lám. 26).

Mediante el análisis de cada una de las esculturas huastecas, destacando los elementos visuales más importantes, ha sido posible constituir grupos homogéneos que se integran porque comparten cualidades específicas. Los temas que se tratan en la escultura no son los mismos que se presentan en el relieve; en aquélla parecen diagnósticos para leer su identidad los atributos que se concentran en los tocados y en las manos; me refiero a la barra que sostiene un conjunto, así como a las anomalías corporales y el hecho de llevar una figura menor sobre la espalda. En el relieve, en cambio, la comprensión del asunto figurado es dificil, pues se recurre a un complejo vocabulario simbólico. La visión conjunta de la escultura huasteca y de los temas que en ella se muestran permitirá una mayor comprensión de su significado.

\section{BIBLIOGRAFIA}

Arte Huaxteco Prehispánico.

1977 Artes de México. Núm 187, Año XXII, Coordinación Beatriz de la Fuente, México

\section{DU SOLIER, Wilfrido.}

1939-40 Estudio arquitectónico de los edificios huaxtecos Anales del Instltato Vacional de Antropologia e Historia, Tomo I, pp. 121-145, México.

1943 Conclusiones sobre el estudio arqueológico de la Huaxteca. El Norte de México y el Sur de Estados Unidos. Tercera Reunión de Mesa Redonda sabre Problemas Antropalógicos de México y Centro Amértia, pp 148-152. Sociedad Mexicana de Antropologia, México.

\section{EKHOLM, Gordon F.}

1944 Excavations at Tampico and Pánuco in The Huasteca, México. Anthropological Papers of The American Museum of Valural History, Vol 38, Núm. 5, pp. 319. 512. American Museum of Natural History, New York

1953 Notas Arqueológicas sobre el Valle de Tuxpan y Areas Circunvecinas. Huastecos, Totonacos y sus Vecinos, Revistá Mexicana de Estudios Antropológicos, Vol XIII, pp 413-421. Sociedad Mexicana de Antropologia, México

\section{GARCÍA PAYÓN, José}

1963 Bibliografia Arquealogica de Veracruz. Universidad de Veracruz, Xalapa. 1974 La Huasteca Historia de Méxio, Vol II, fasciculos 21 y 22, pp. 115-140, Salvat, México 
DOI: http://dx.doi.org/10.22201/iie.18703062e.1982.50\%20Tomo\%201.1133

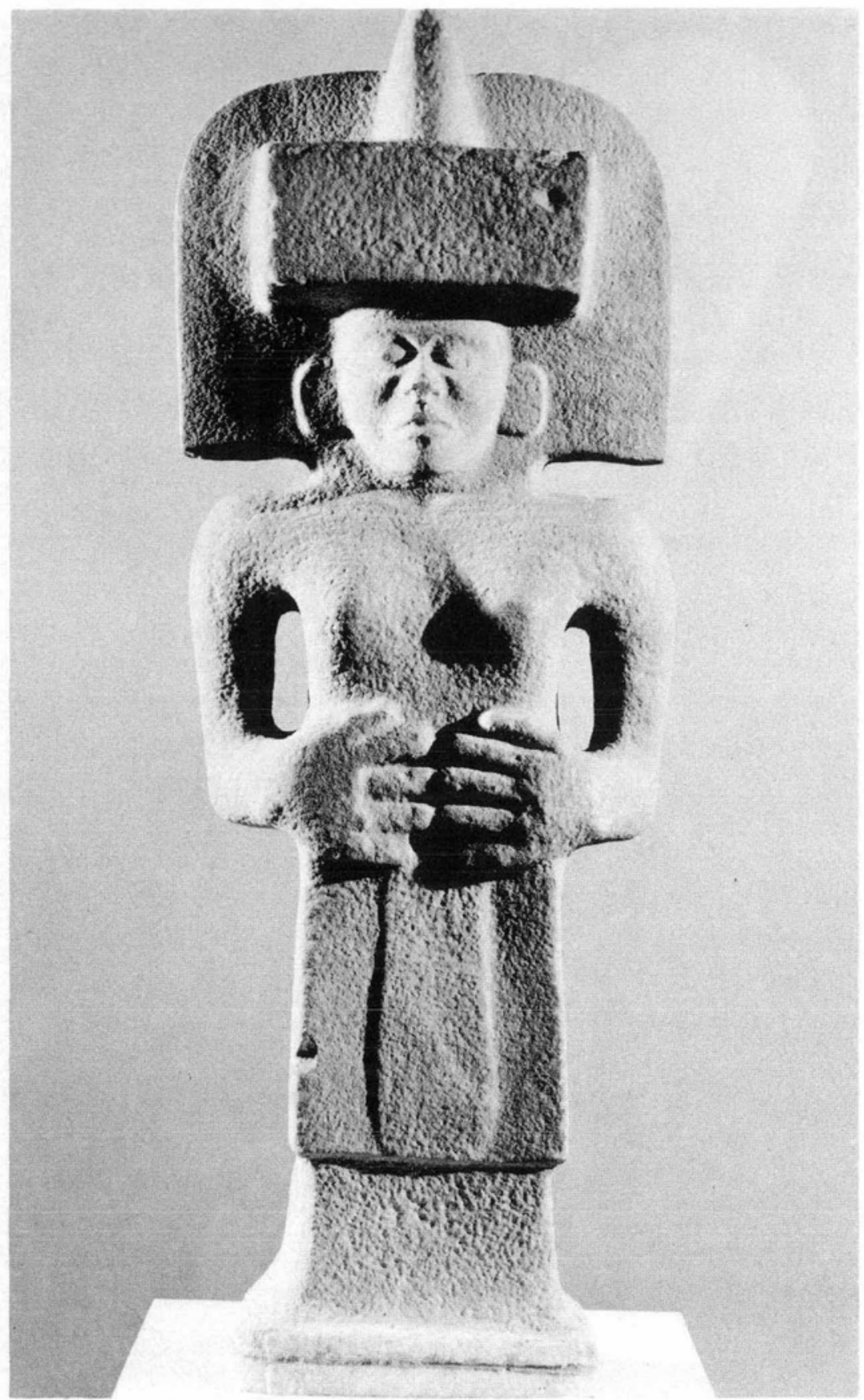

Lámina 1. Figura femenina. Museo Nacional de Antropología, México. Foto: Beatriz de la Fuente. 


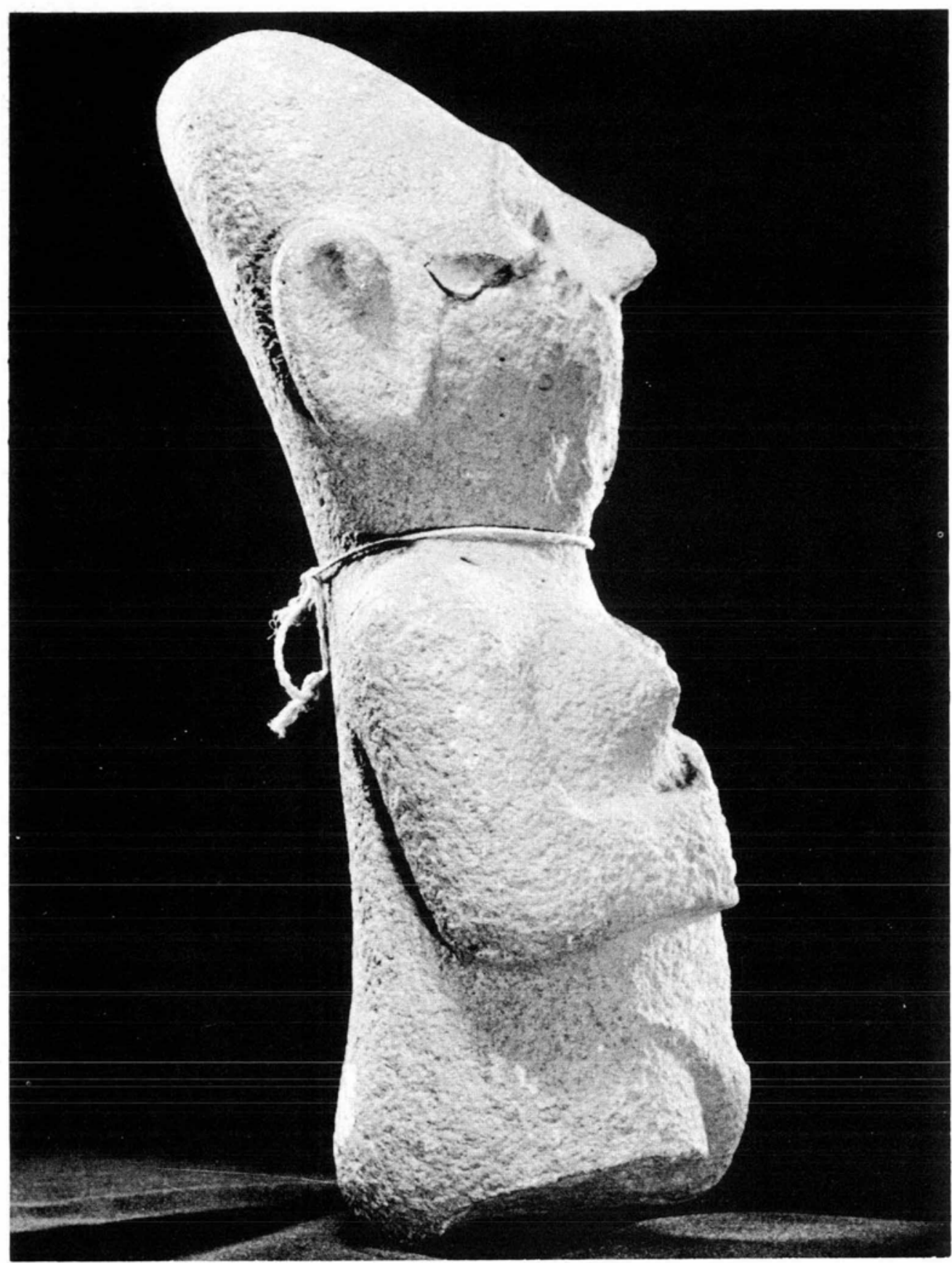

Lámina 2. Figura femenina desnuda. Bodegas del Museo Nacional de Antropología, México. 


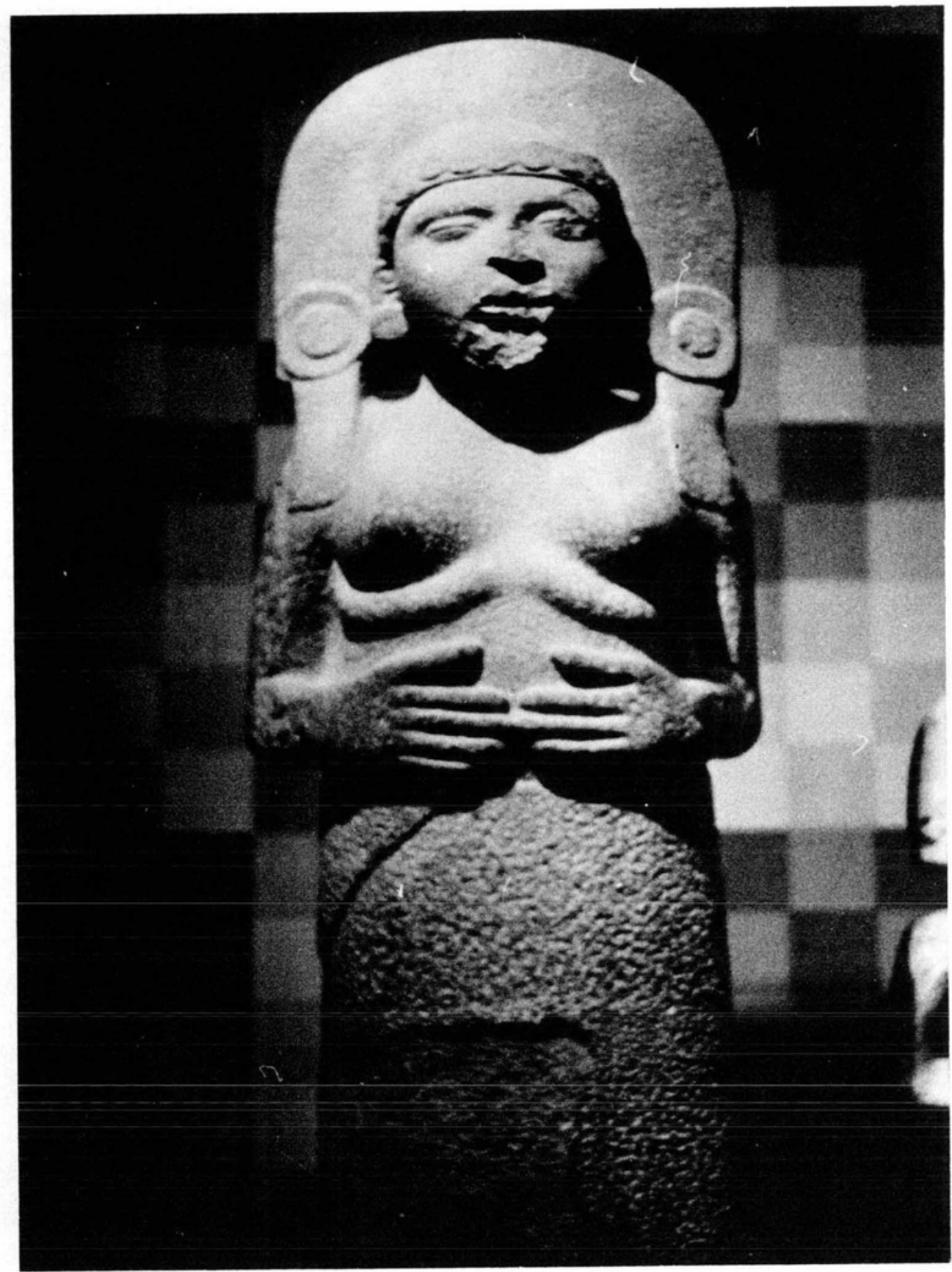

Lámina 3. Figura femenina con pliegues bajo los pechos. American Museum of Natural History, Nueva York. Foto: Nelly Gutiérrez Solana. 


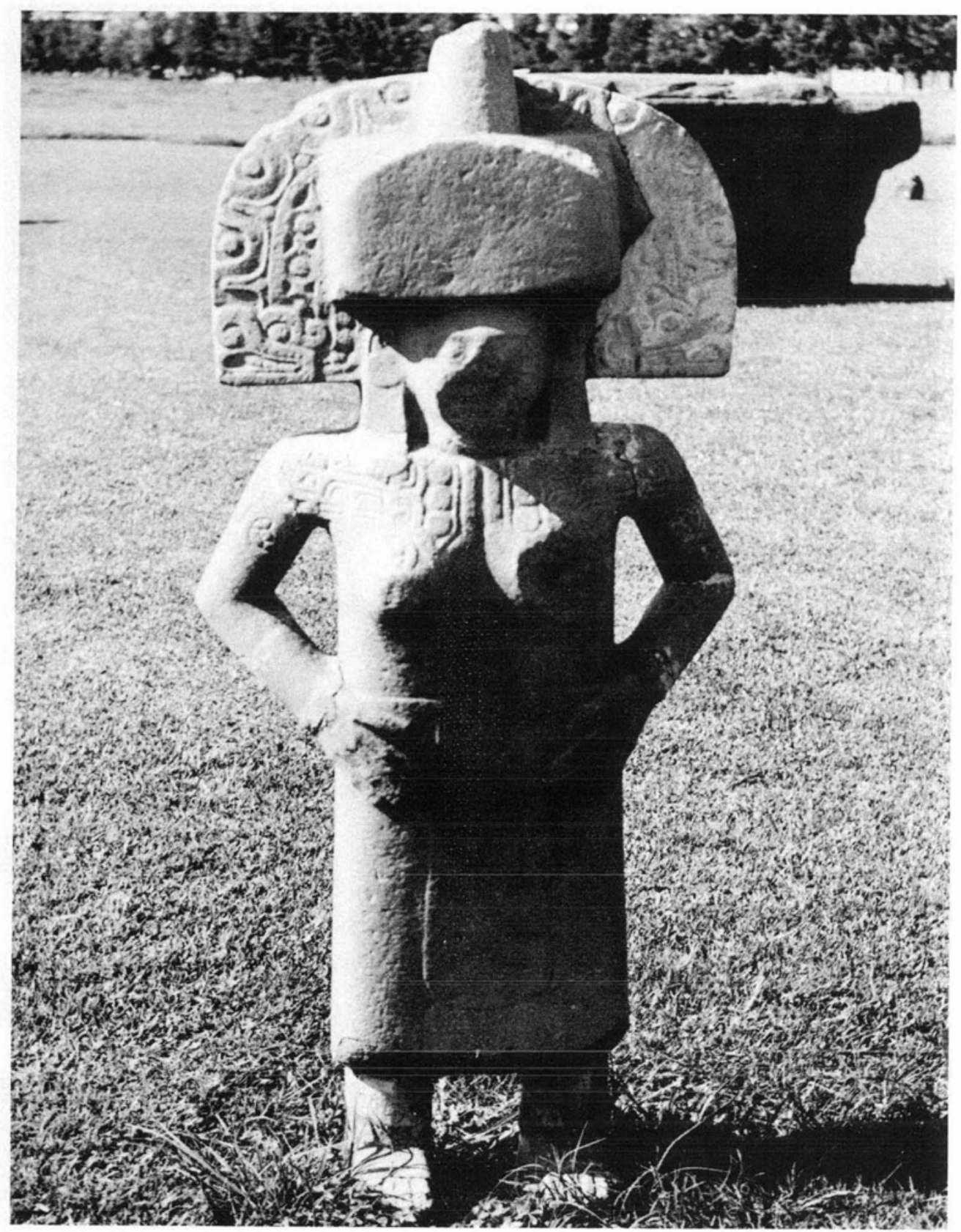

Lámina 4. Figura femenina con tocado de abanico, bloque rectangular y gorro cónico. Museo de Antropologia de la Universidad Veracruzana, Xalapa, Veracruz. Foto: Beatriz de la Fuente. 


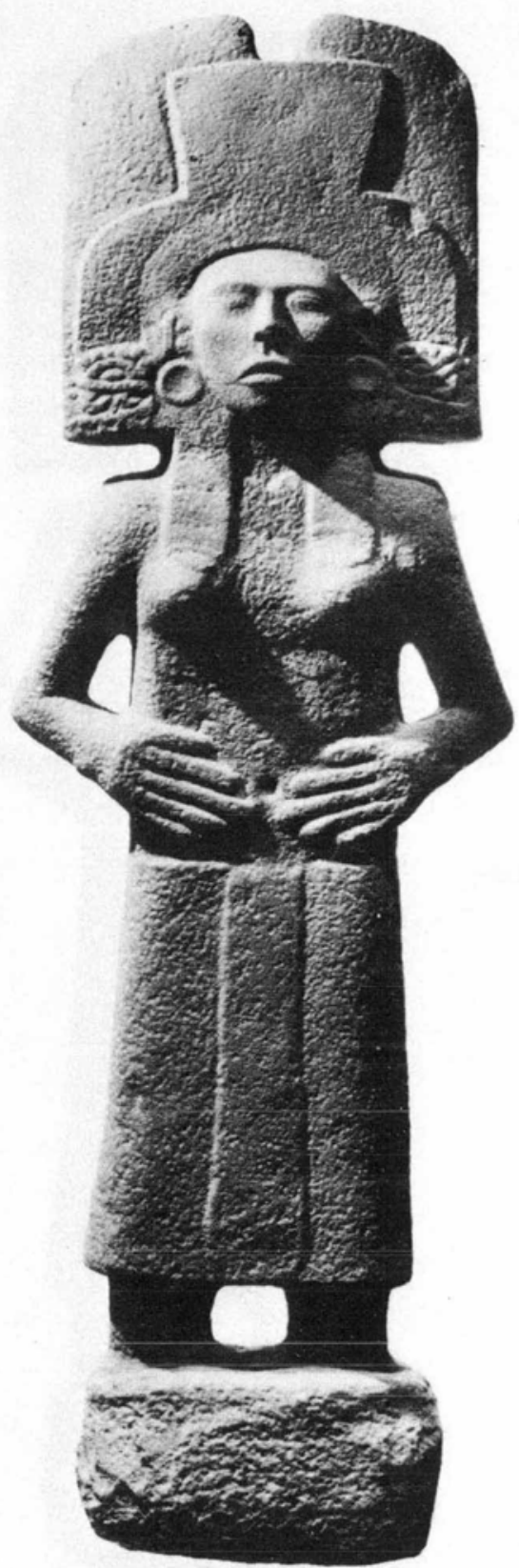

Lámina 5. Figura femenina con tocado de abanico. (Vista anterior). Foto Cortesia del Museum für Völkerkunde, Berlin. 


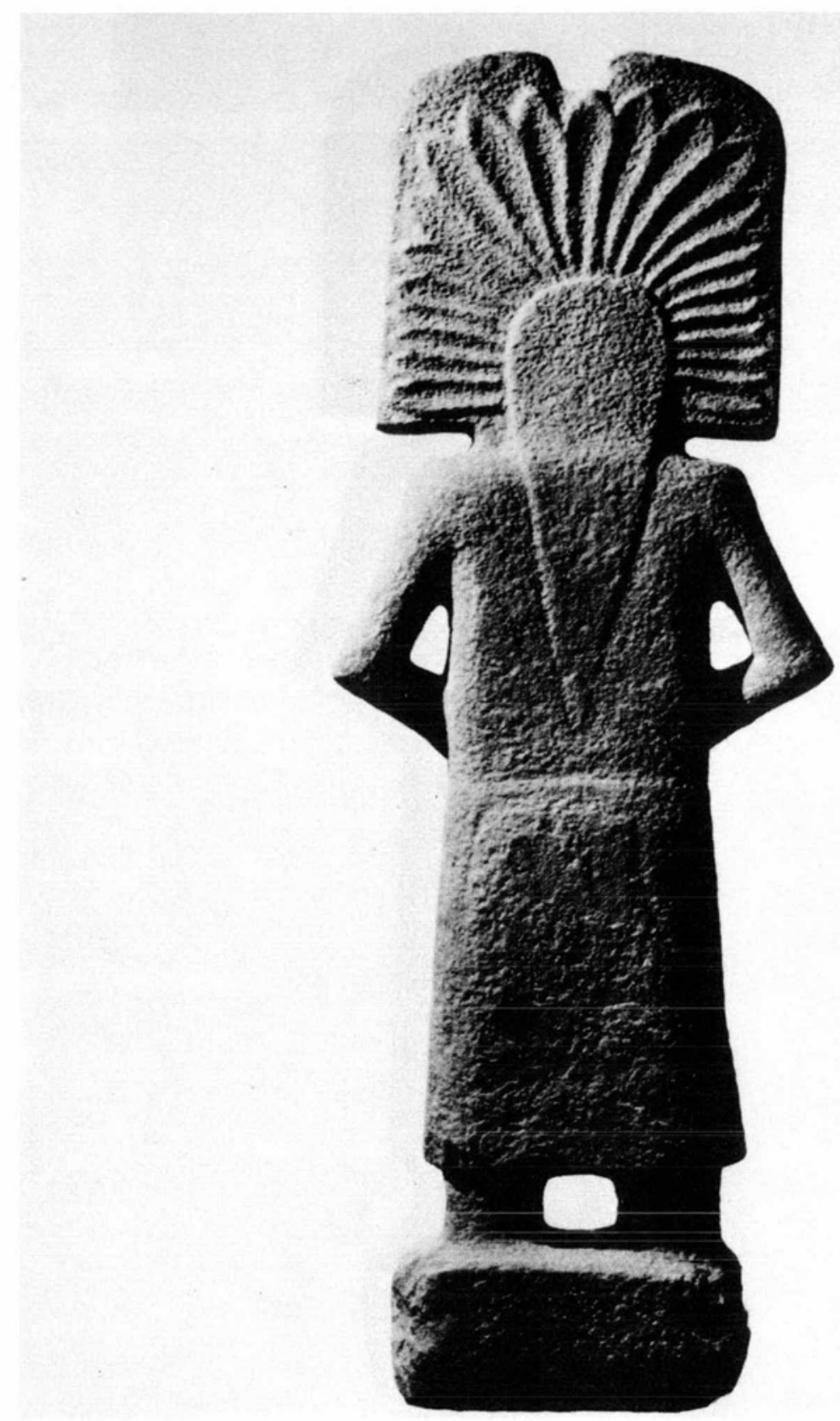

Lámina 6. Figura femenina con tocado de abanico. (Vista posterior). Foto Cortesía del Museum für Völkerkunde, Berlín. 


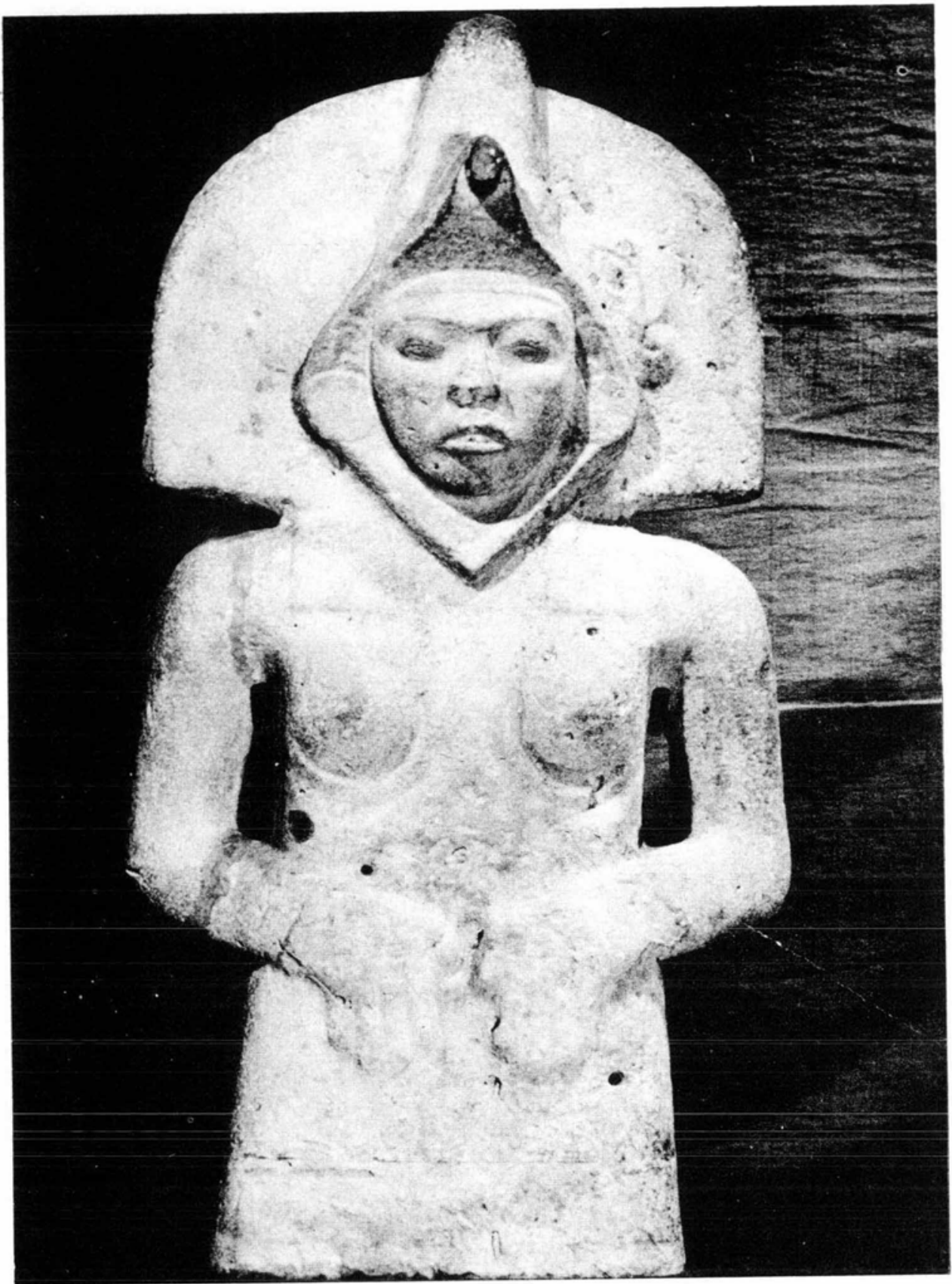

Lámina 7. Figura femenina con tocado zoomórfico y de abanico. Museo Nacional de Antropología, México. Foto: Beatriz de la Fuente. 


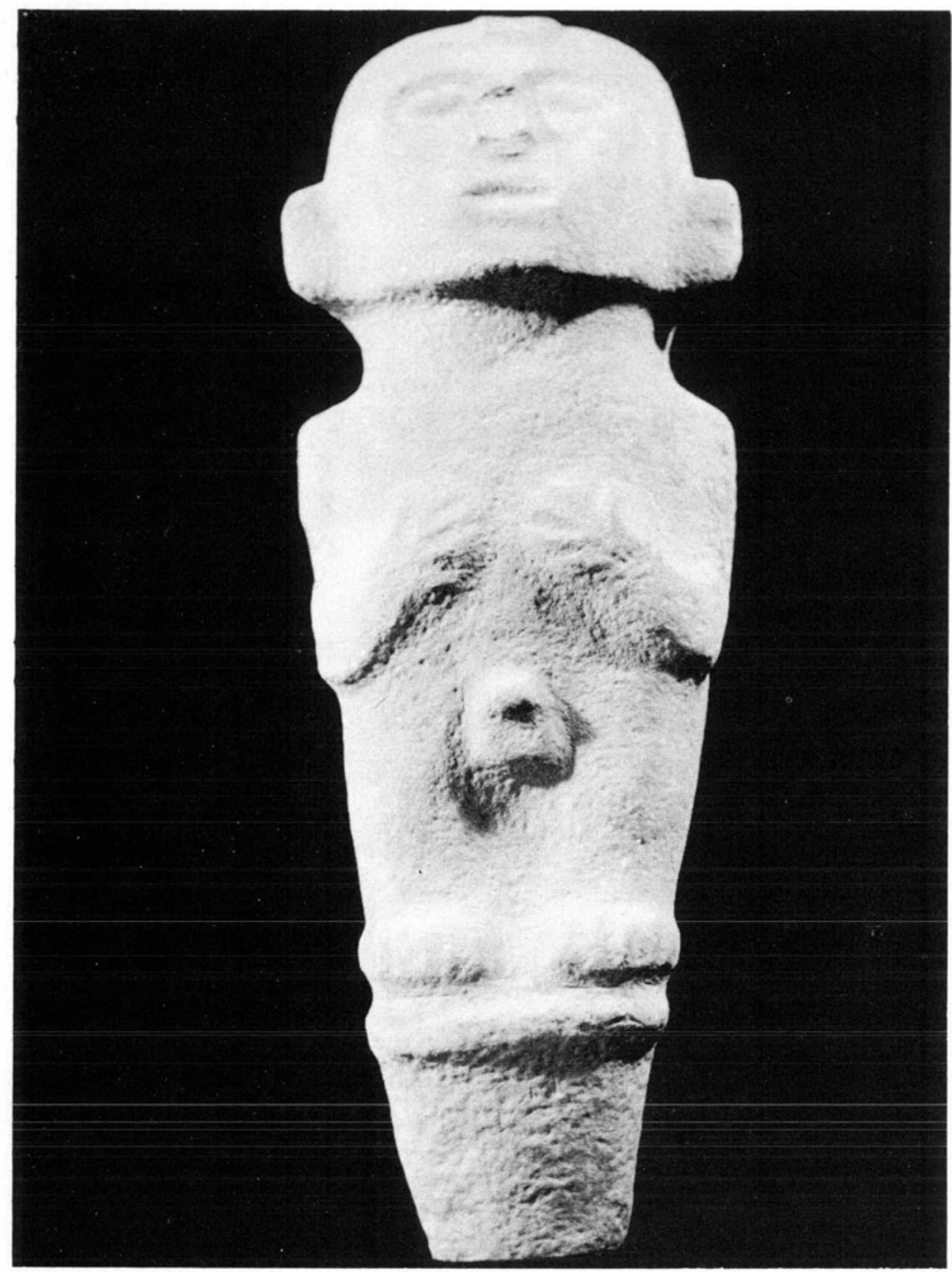

Lámina 8. Figura masculina desnuda. Museo de Antropologia de la Universidad Veracruzana, Xalapa, Veracruz. Foto: José Guadalupe Victoria. 


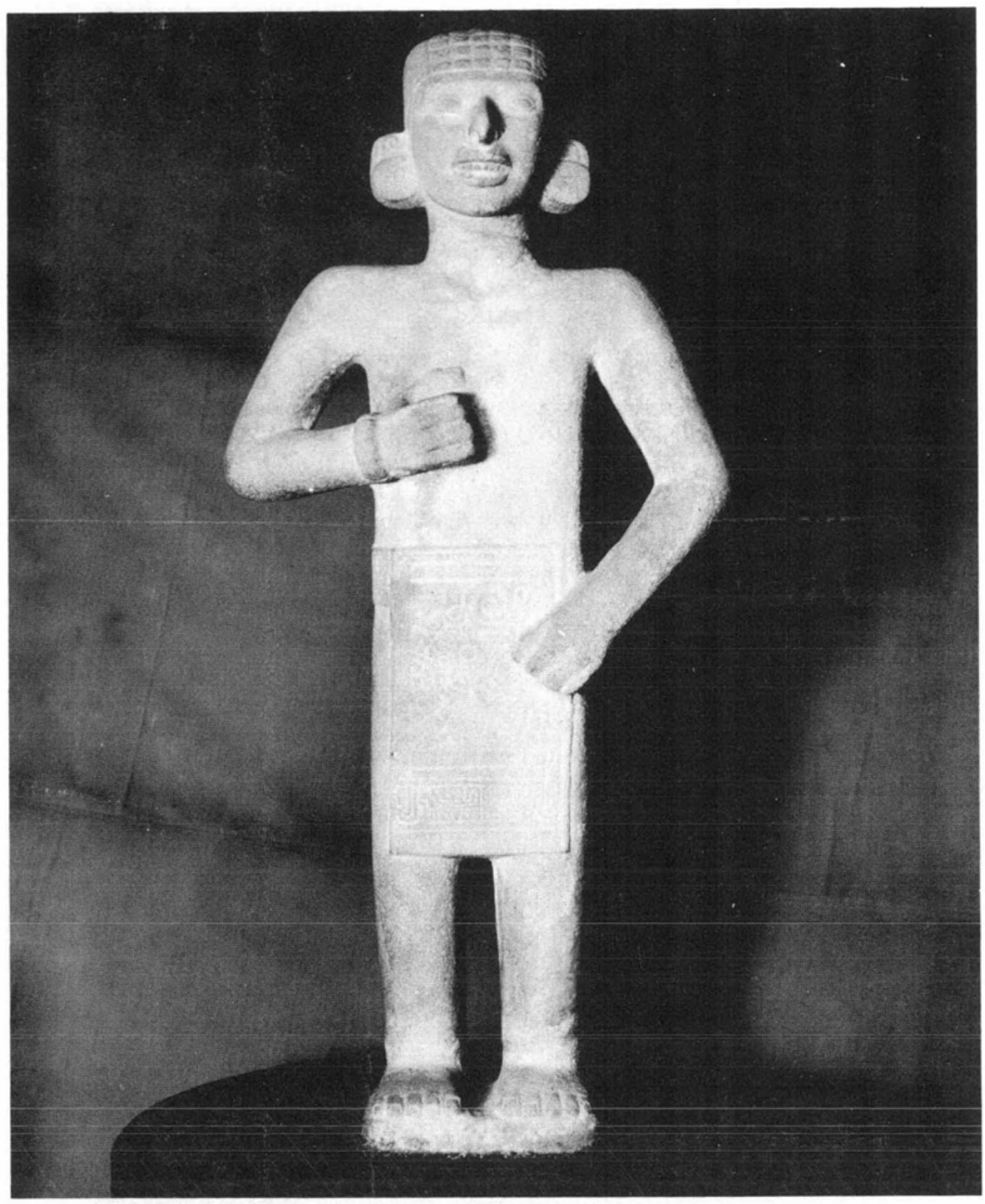

Lámina 9. Figura masculina con máxtlatl decorado. Procede de Ajalpan, Querétaro. Museo Nacional de Antropología, México. Foto: Guillermina Vázquez. 


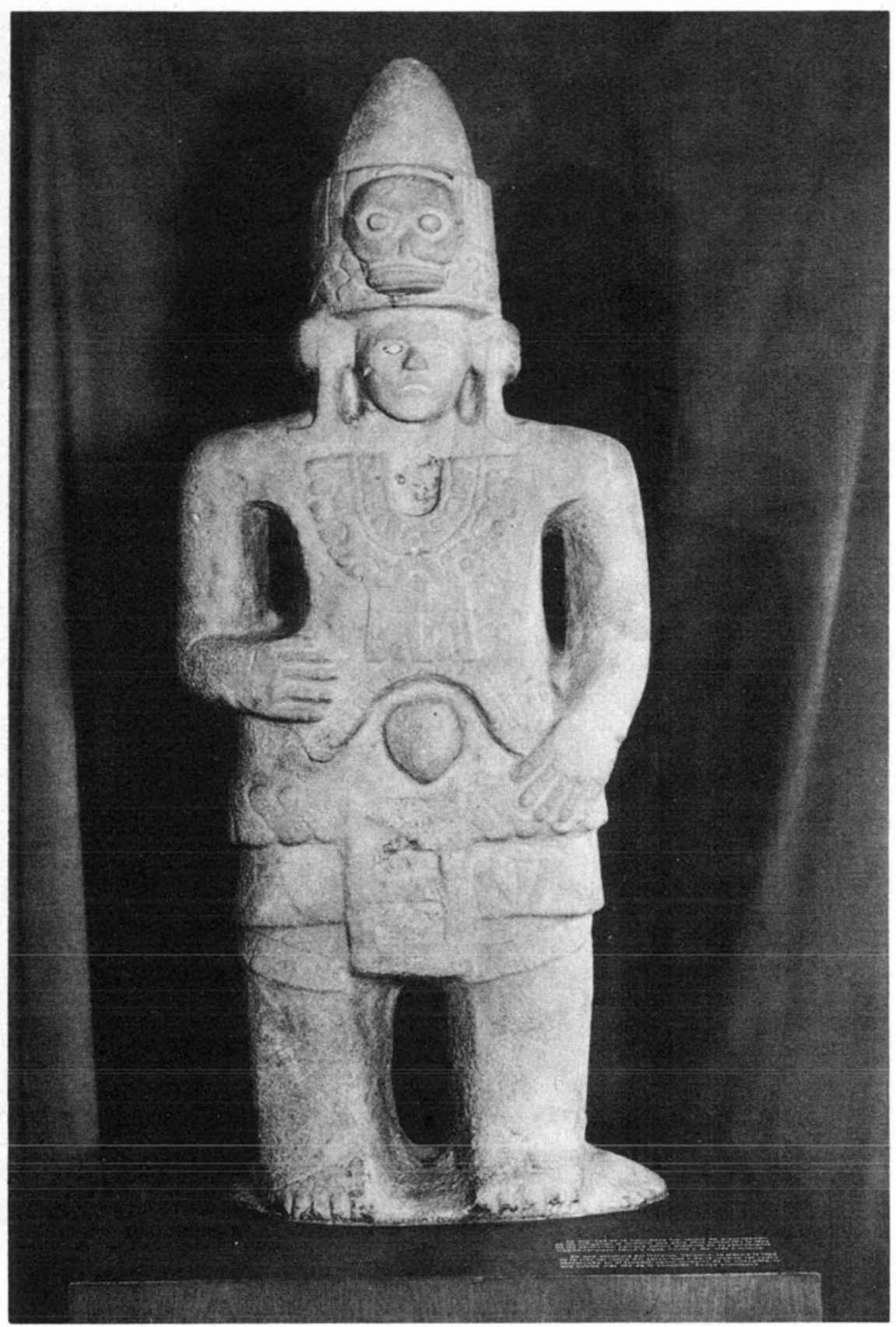

Lámina 10. Figura masculina con tocado cónico. Procede de El Naranjo, Veracruz. Museo Nacional de Antropologia, México. Foto: Guillermina Vázquez. 


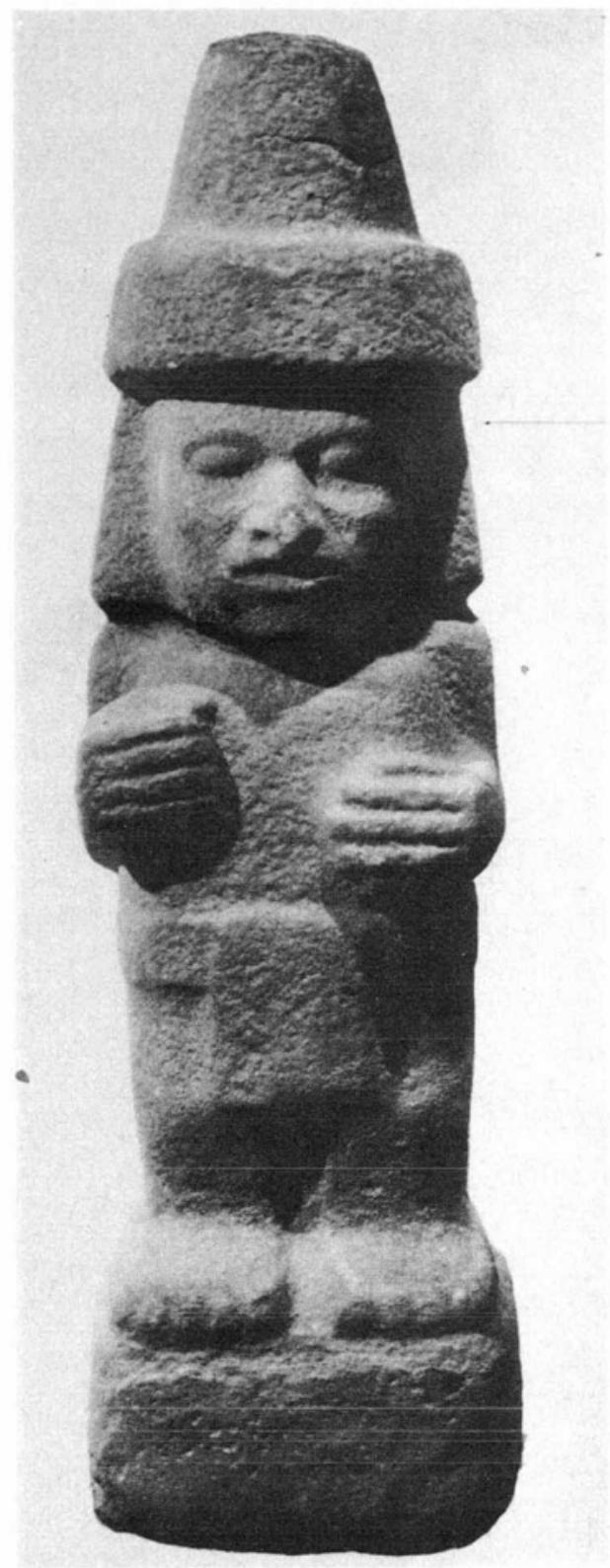

Lámina 11. Figura masculina con tocado cónico. Procede de Tanquián, San Luis Potosi. Foto cortesía del Museum für Völkerkunde, Berlin.

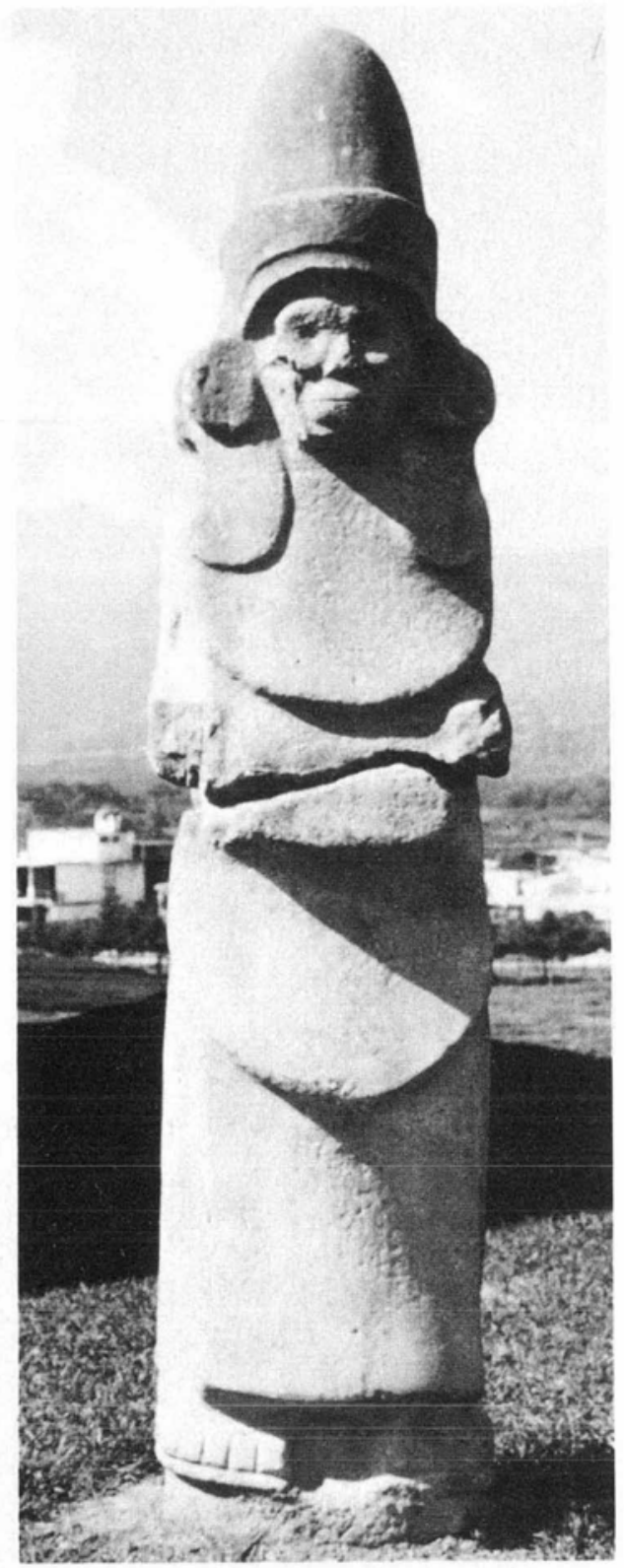

Lámina 12. Figura masculina con tocado cónico. Museo de Antropología de la Universidad Veracruzana, Xalapa, Veracruz. Foto: Beatriz de la Fuente. 


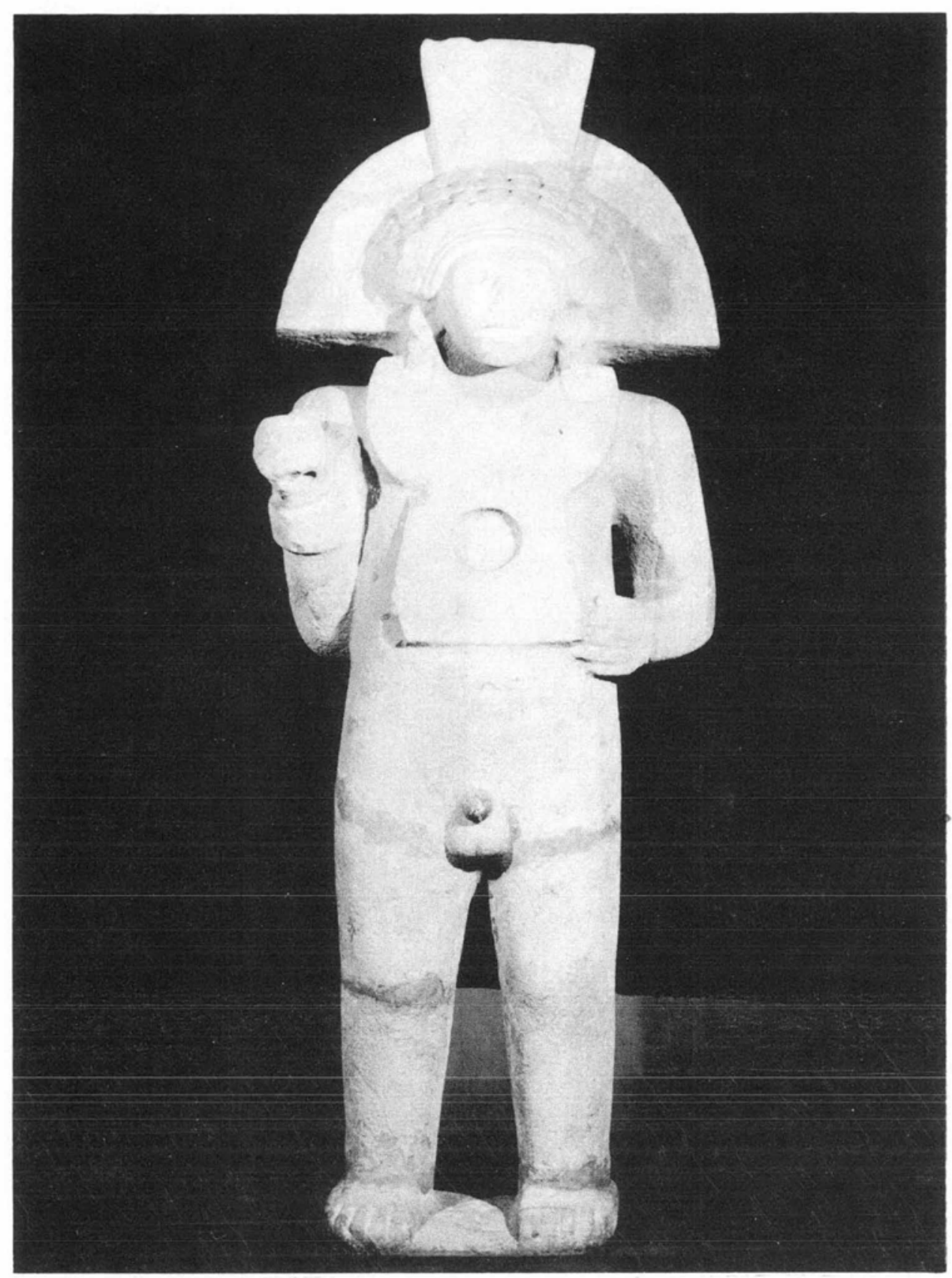

Lámina 13. Figura masculina con tocado de abanico. Museo Nacional de Antropología, México. Foto: Guillermina Vázquez. 
DOI: http://dx.doi.org/10.22201/iie.18703062e.1982.50\%20Tomo\%201.1133

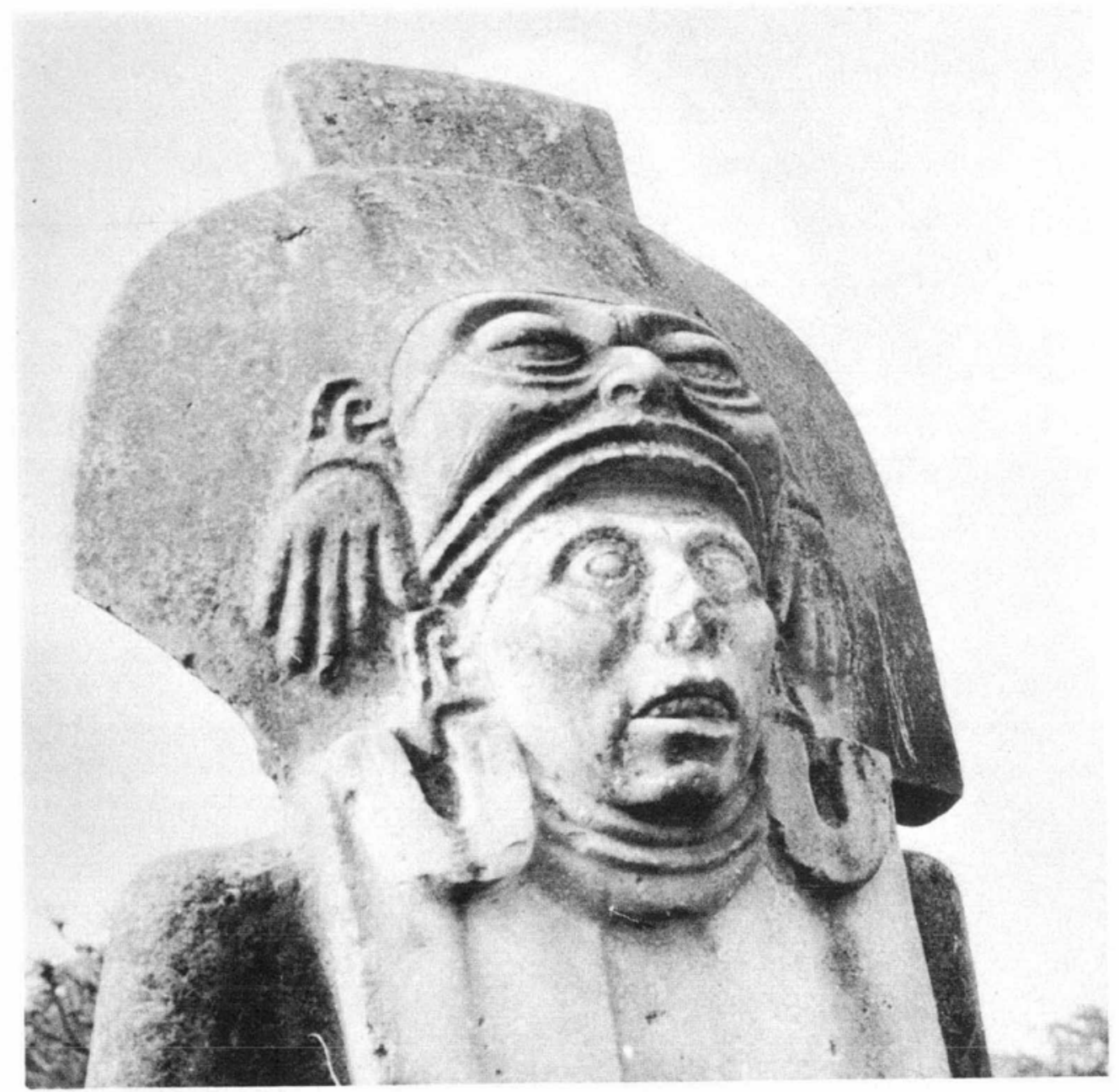

Lámina 14. Figura masculina con tocado antropomorfo. (Detalle). Amatlán, Veracruz. Foto: Roberto Williams Carcía. 
DOI: http://dx.doi.org/10.22201/iie.18703062e.1982.50\%20Tomo\%201.1133

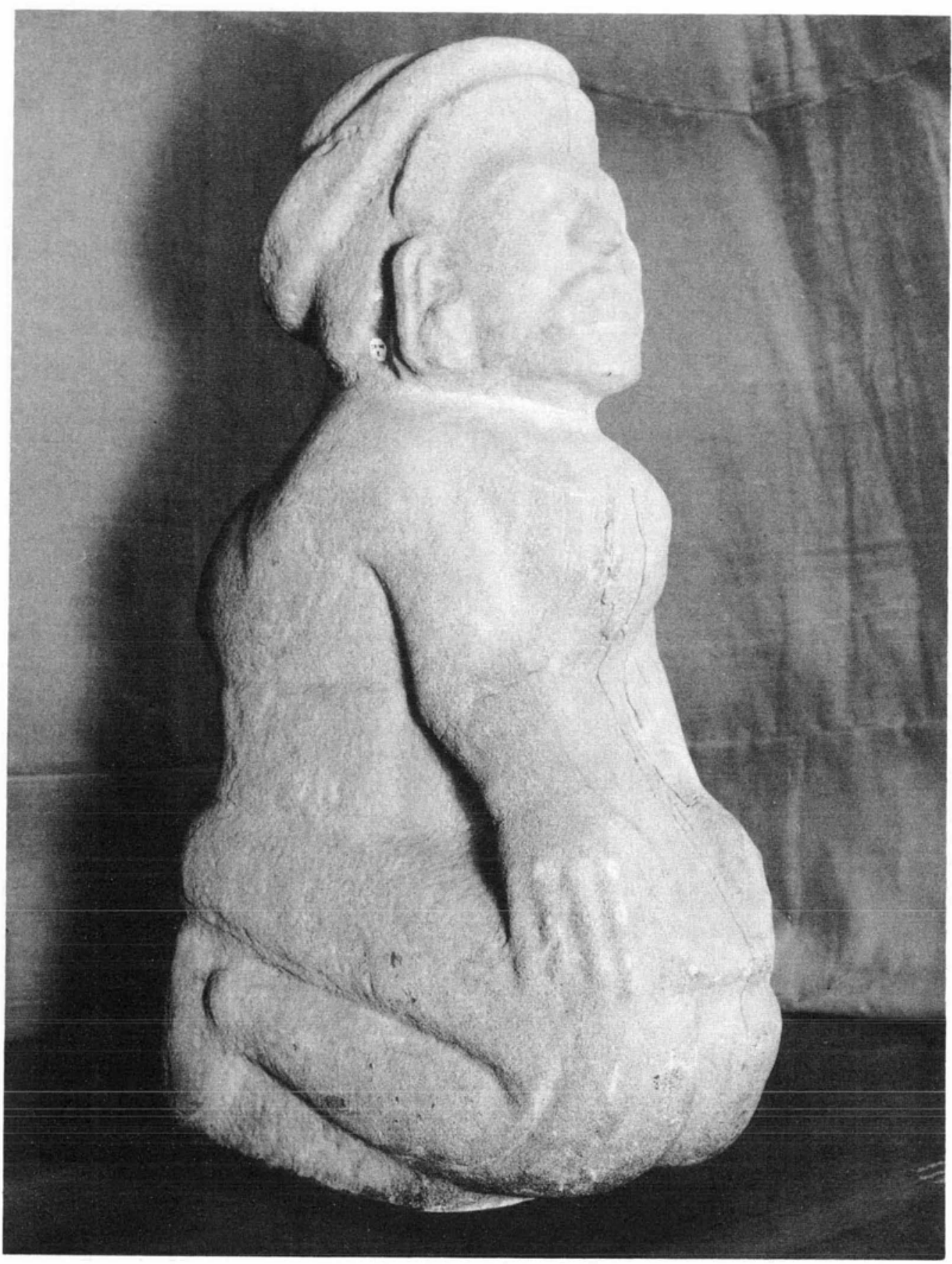

Lámina 15. Figura masculină jorobada. Museo Nacional de Antropología, México. Foto: Guillermina Vázquez. 
DOI: http://dx.doi.org/10.22201/iie.18703062e.1982.50\%20Tomo\%201.1133

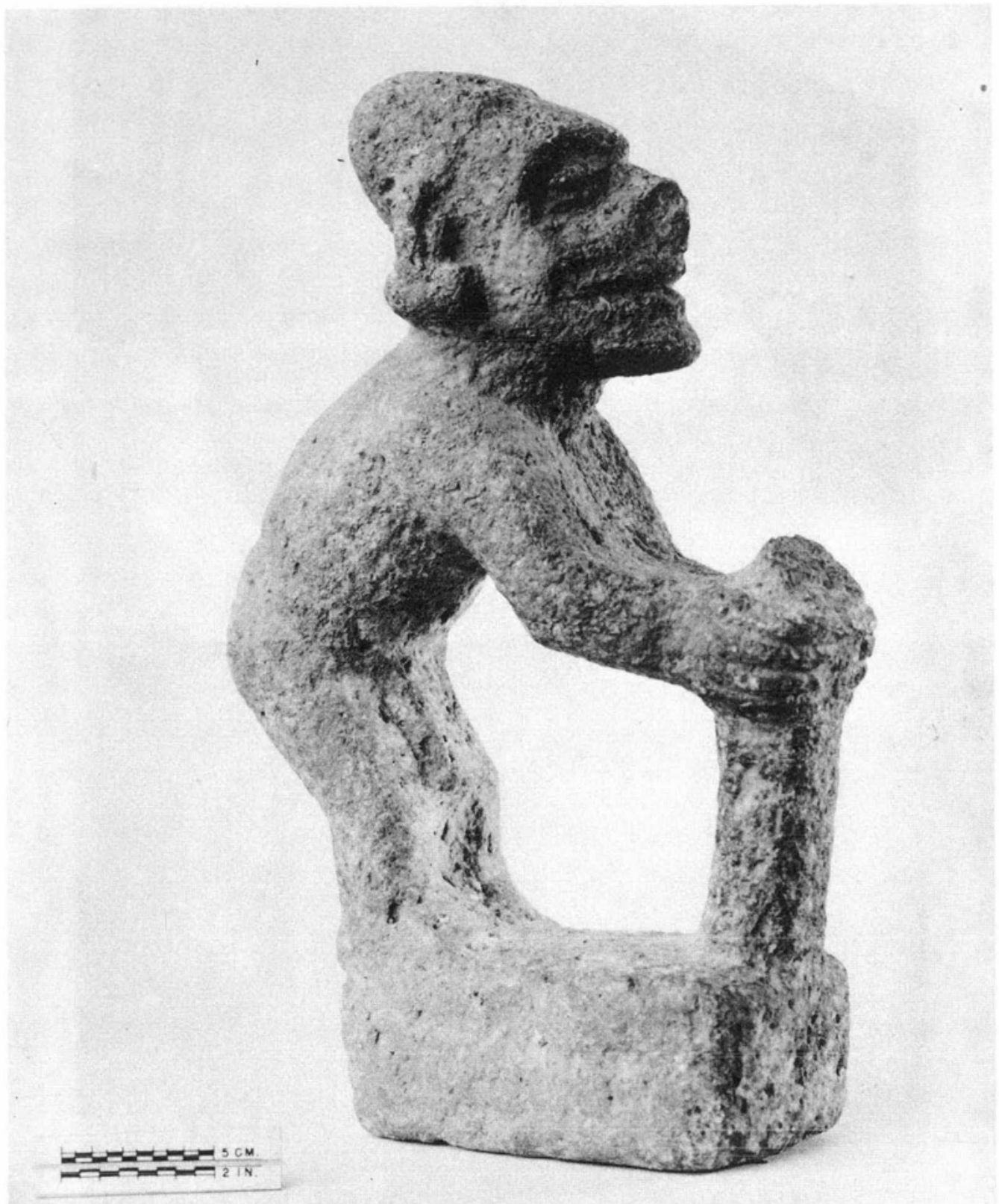

Lámina 16. Figura masculina que sostiene una barra entre las manos. Foto Cortesía del National Museum of Natural History, Smithsonian Institution, Washington. 


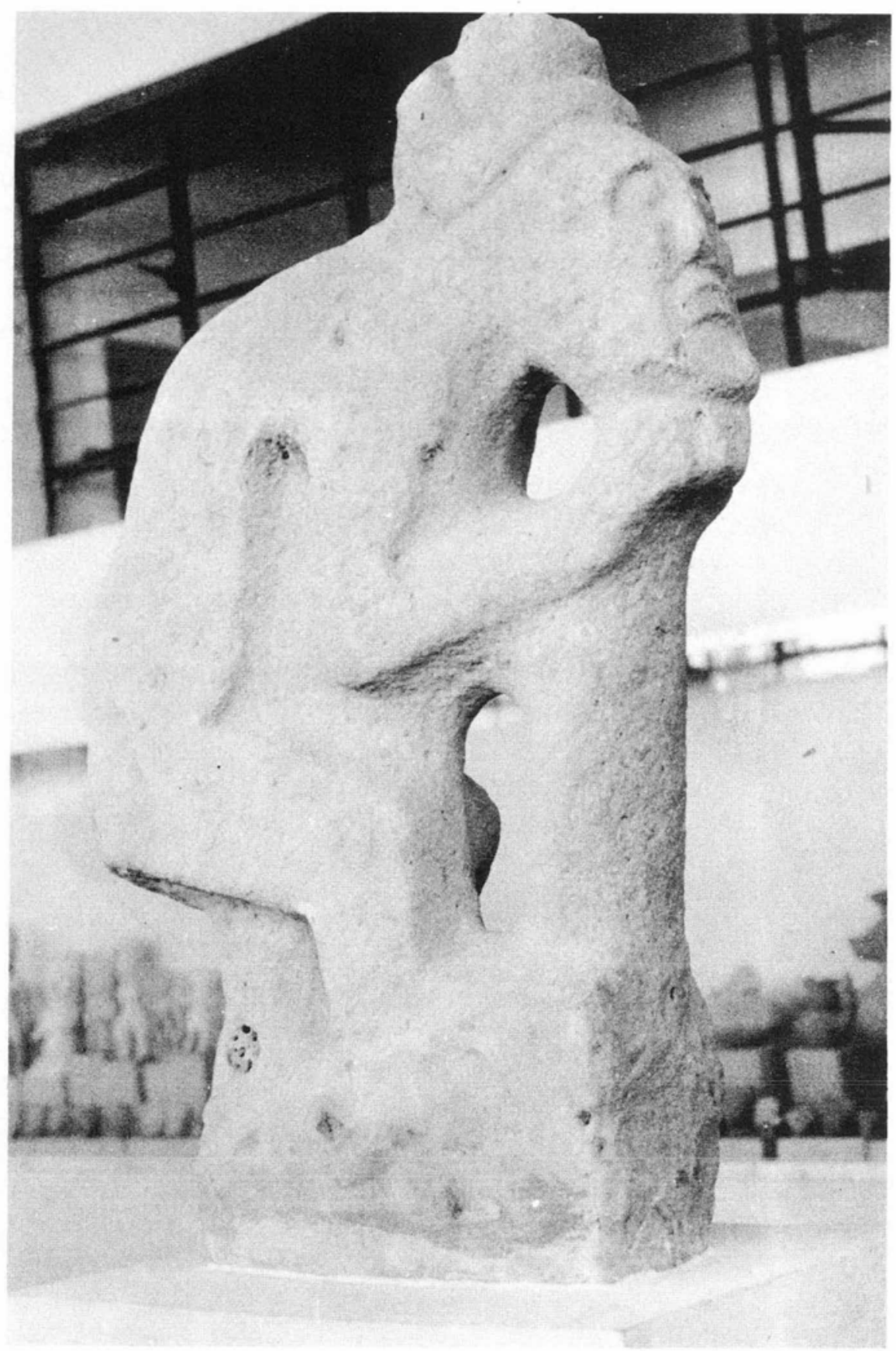

Lámina 17. Figura masculina jorobada que sostiene una barra entre las manos. Museo Regional de Geología, Paleontología y Arqueología de Tampico Alto, Veracruz. Foto: Nelly Gutiérrez Solana. 


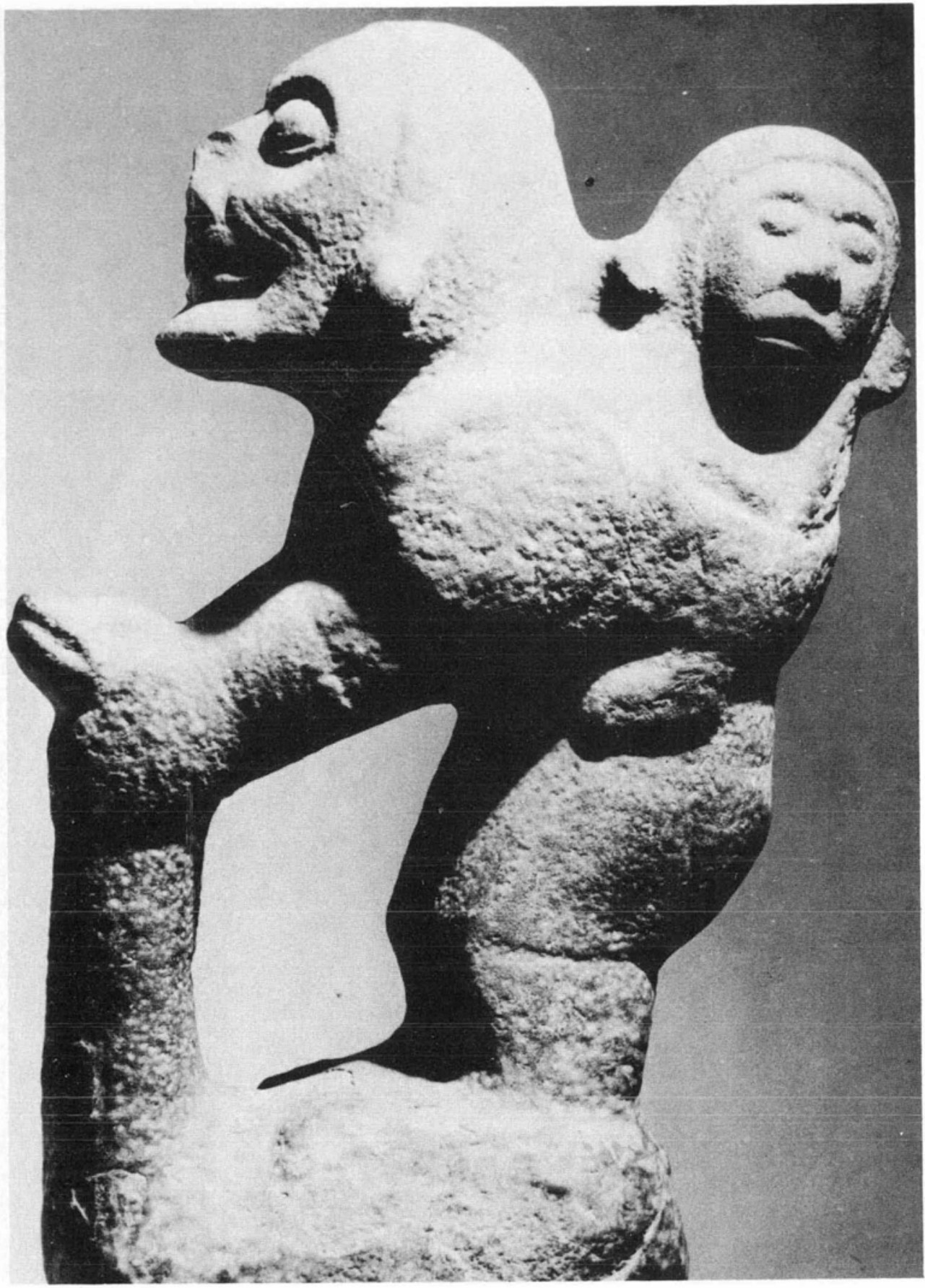

Lámina 18. Figura masculina de anciano que sostiene una serpiente entre sus manos y lleva un niño a cuestas. Foto Cortesía del Musée de l'Homme, París. 


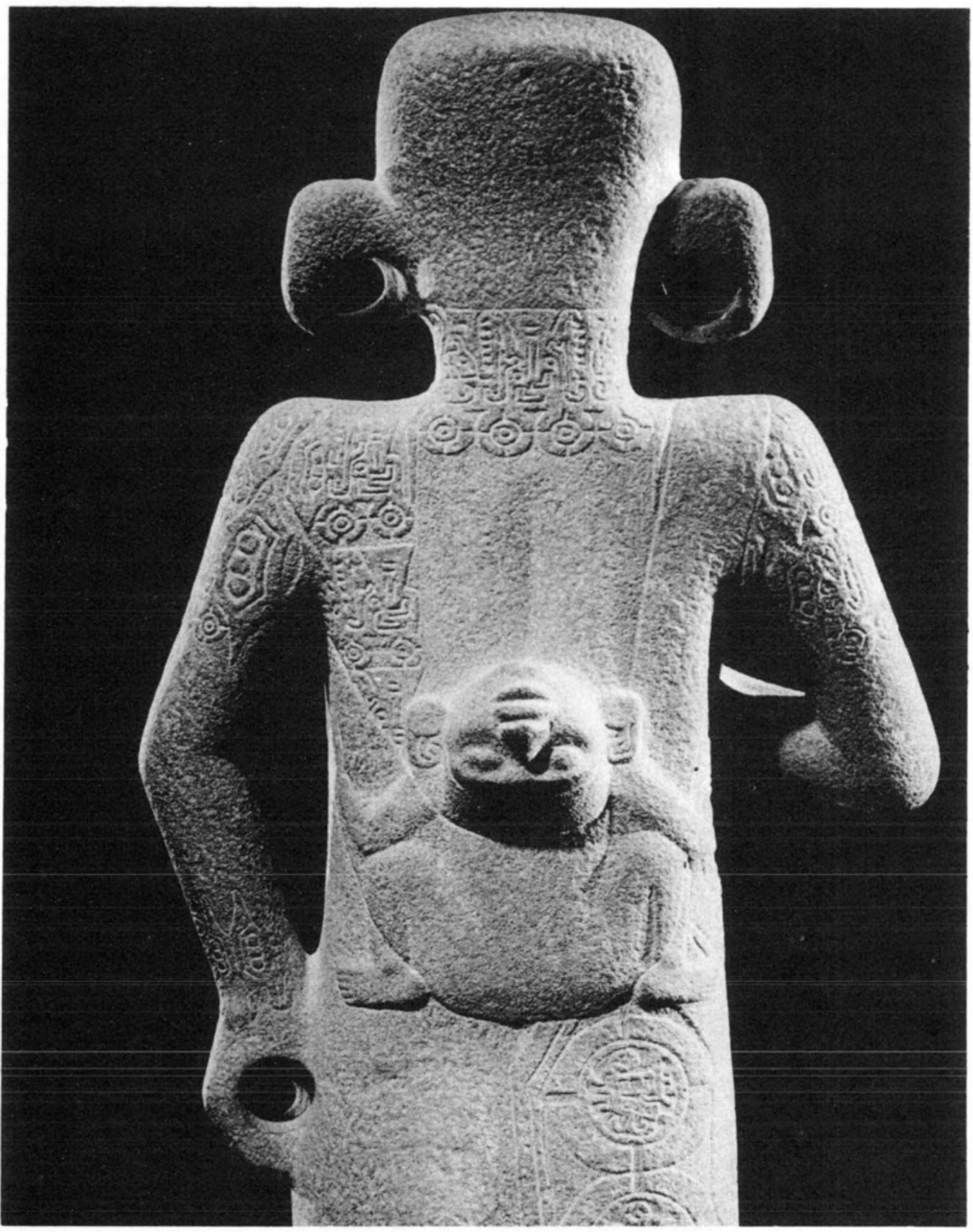

Lámina 19. Figura masculina con otra menor a cuestas. "El Adolescente". (Detalle de su vista posterior). Procede de Tamuín, San Luis Potosí. Museo Nacional de Antropología, México. 


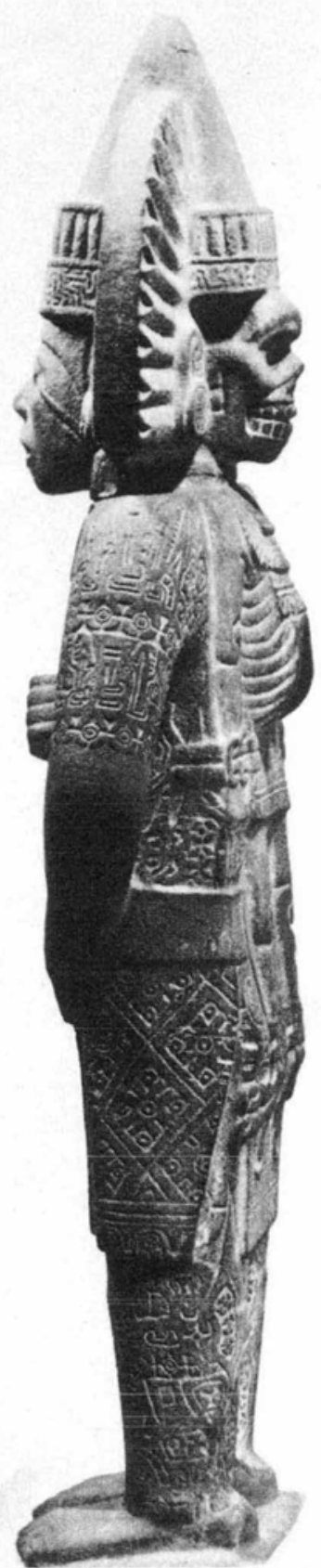

Lámina 20. Figura masculina con un esqueleto a cuestas. Procede de Tancuayalab, San Luis Potosí. Foto Cortesía de Brooklyn Museum, Nueva York.

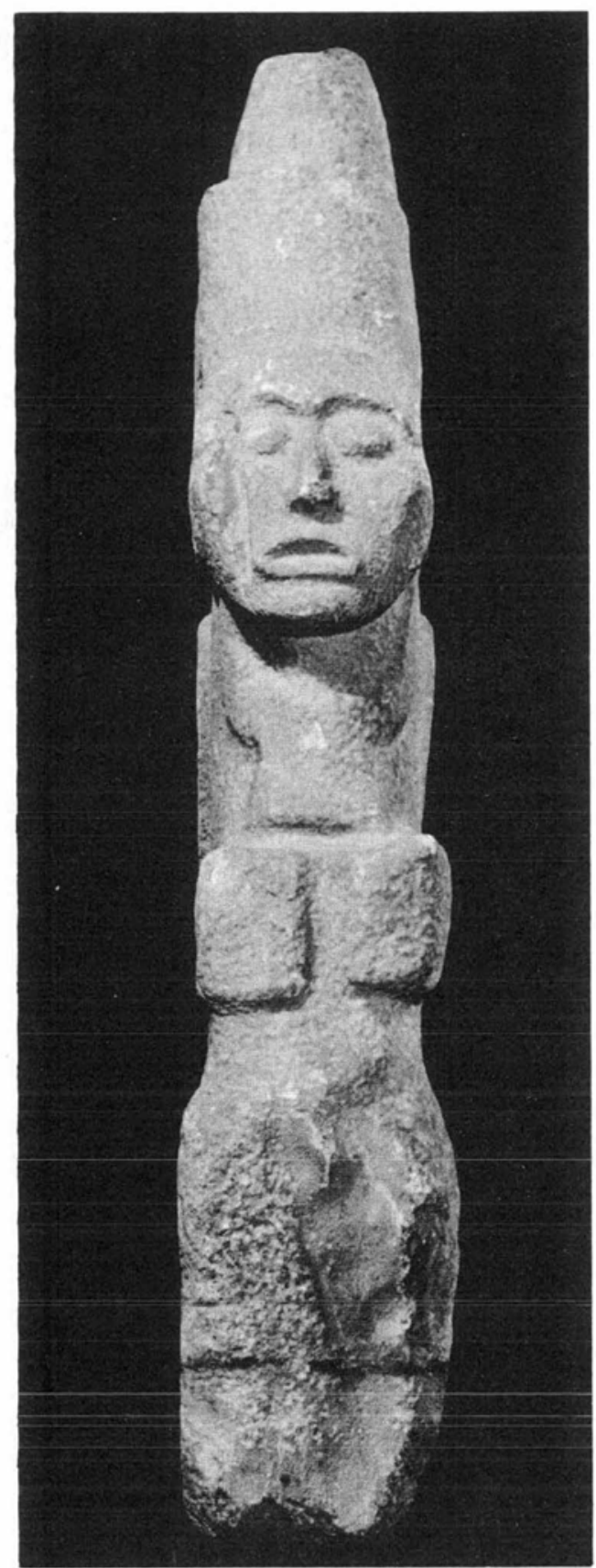

Lámina 21. Figura humana cuyo sexo no es determinable. Bodegas del Museo Nacional de Antropología, México. 


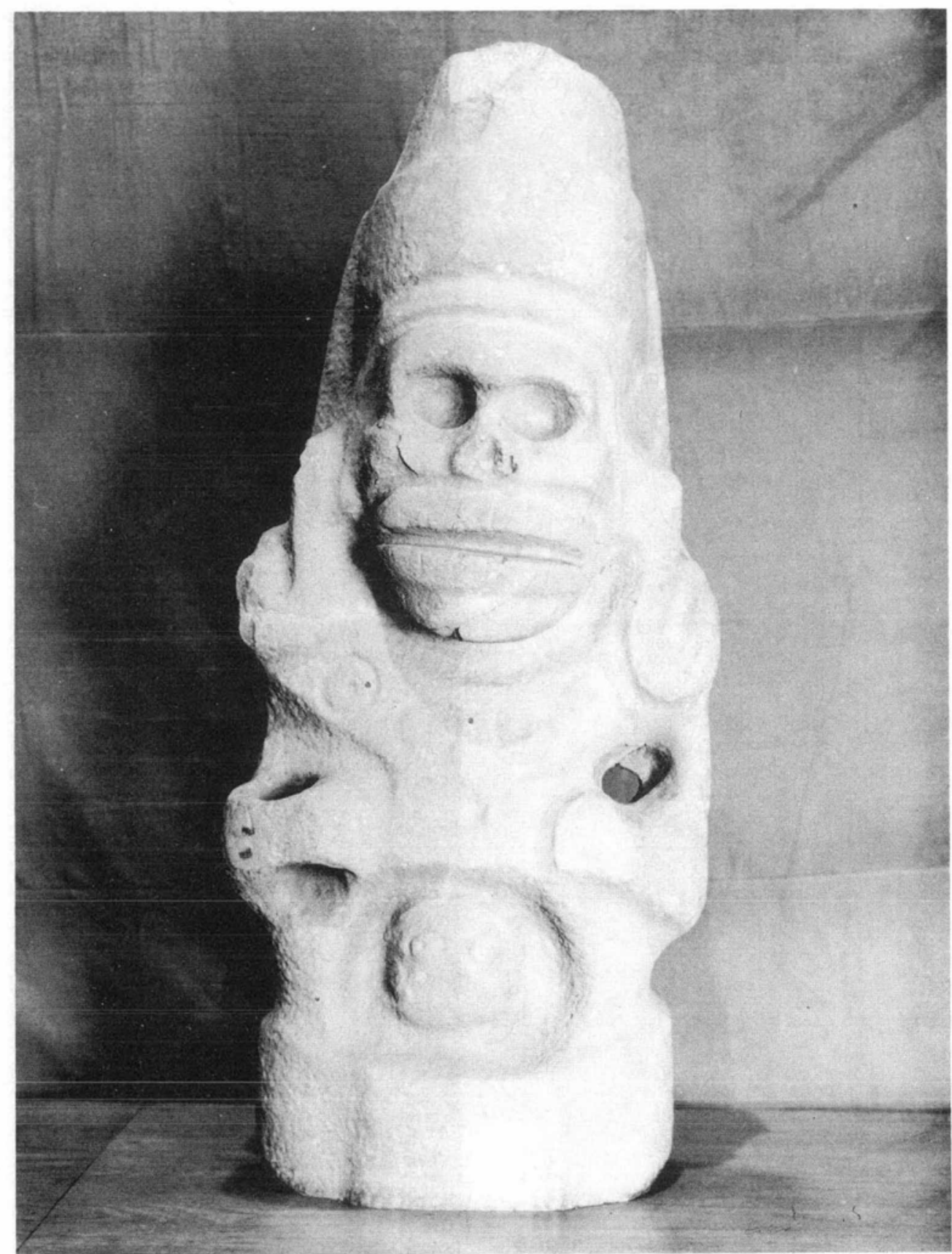

Lámina 22. Figura humana con rostro descarnado. Procede de Pánuco, Veracruz, Museo Nacional de Antropología, México. Foto: Guillermina Vázquez. 


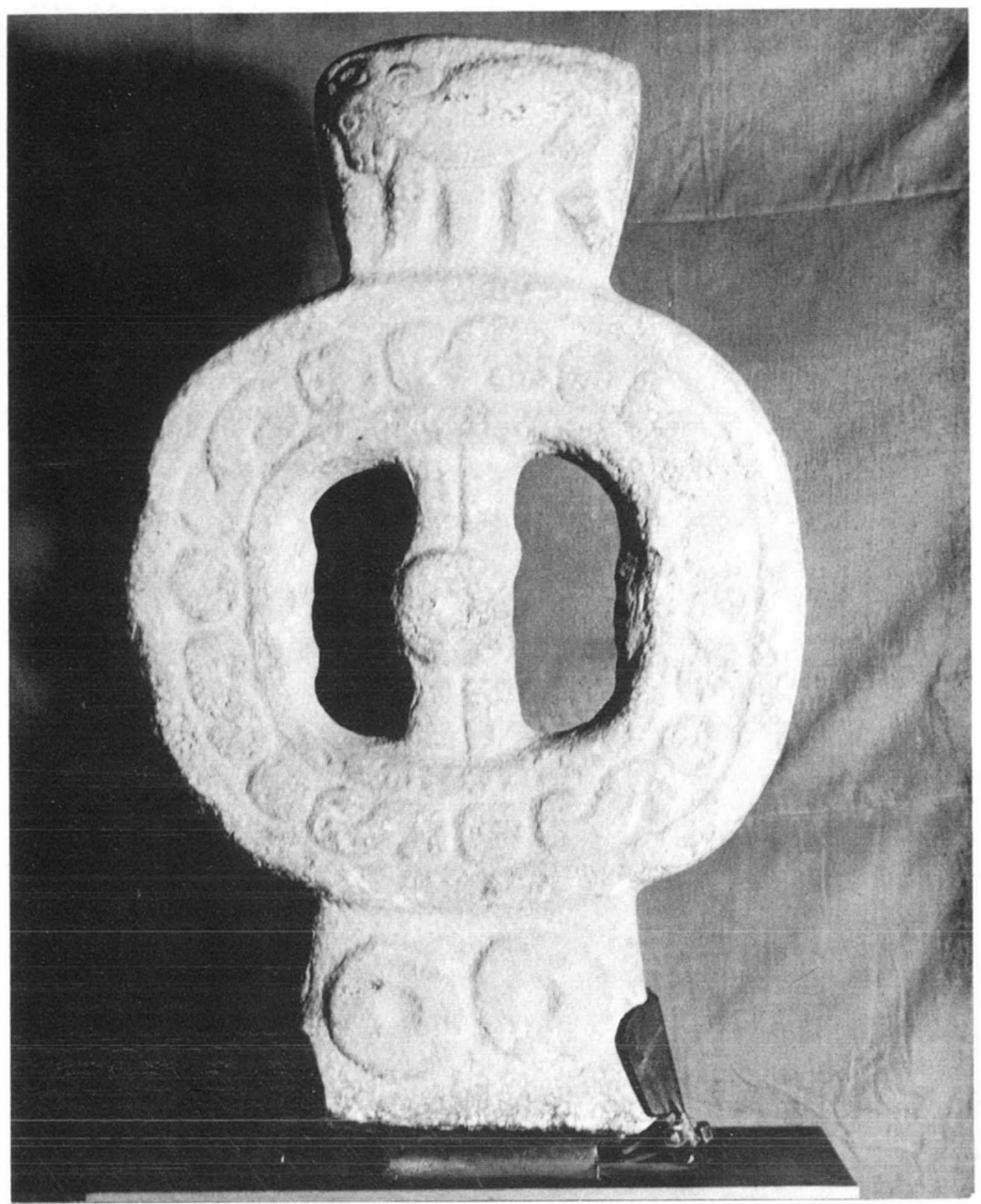

Lámina 23. Disco con fecha del Tonalpohualli. Procede de Tampacayal, Veracruz. Museo Nacional de Antropología, México. Foto: Guillermina Vázquez. 


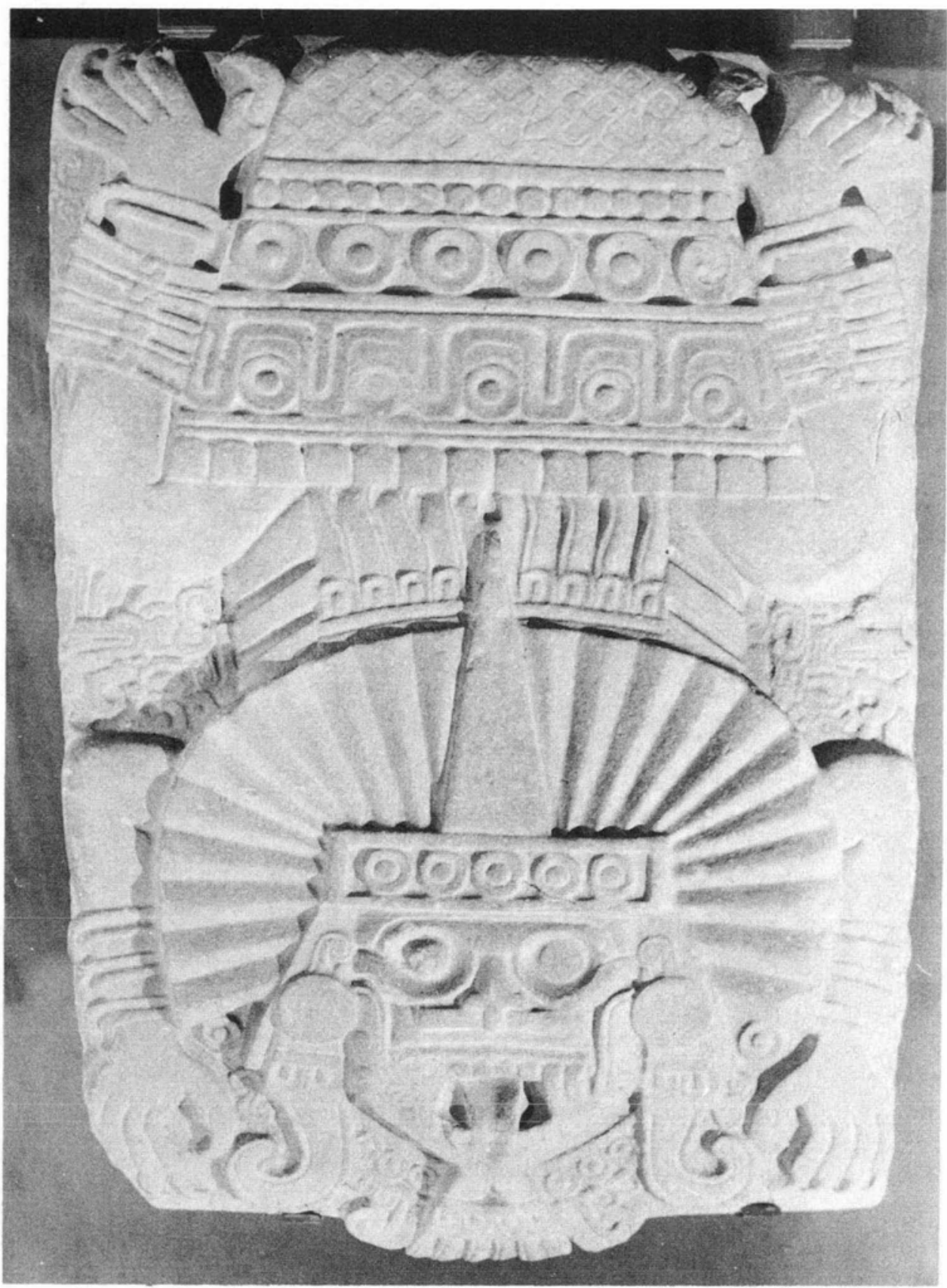

Lámina 24. Losa con figura antropomorfa en relieve. Procede de Tepetzintla, Veracruz. Museo Nacional de Antropología, México. Foto: Beatriz de la Fuente. 


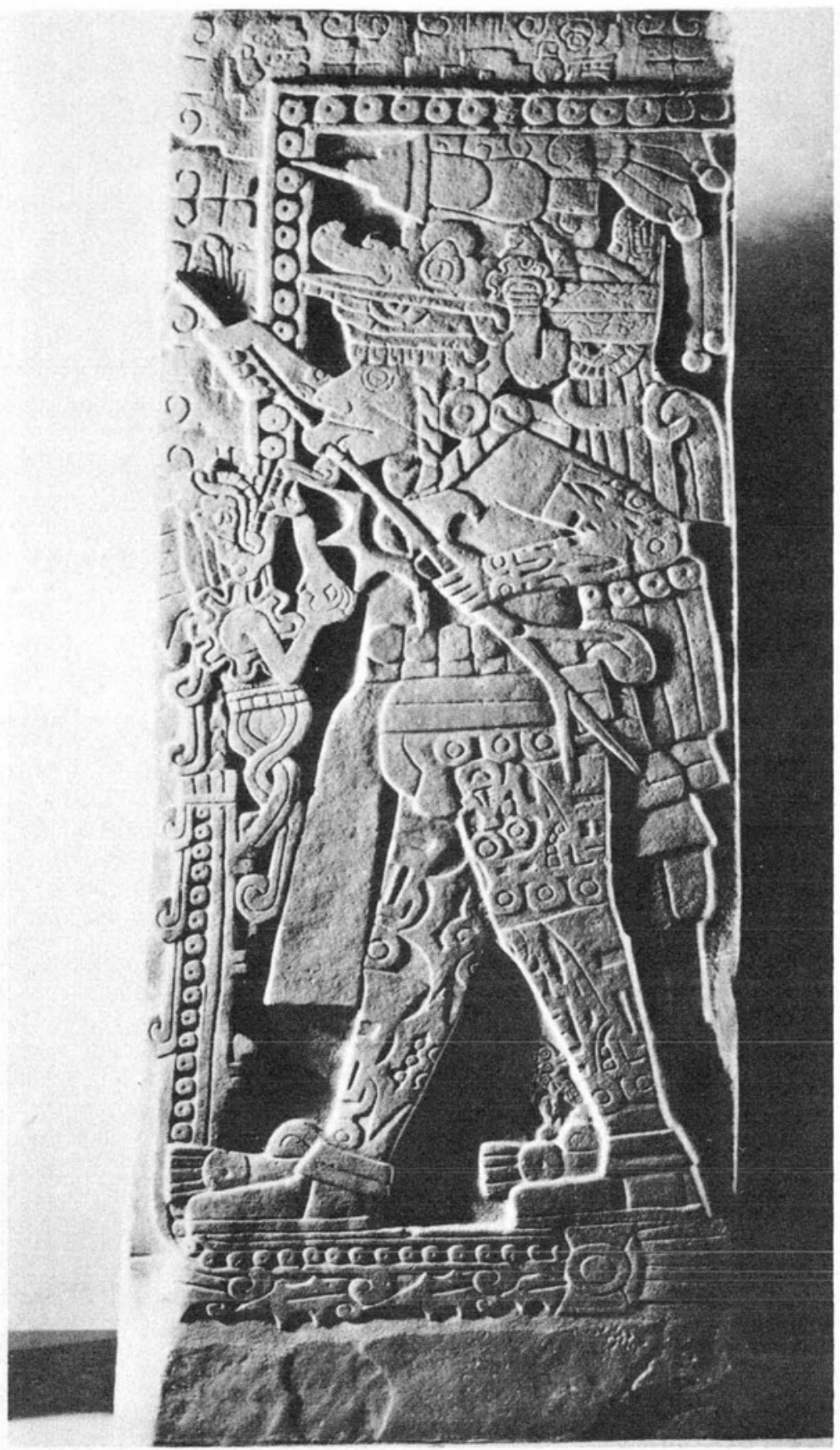

Lámina 25. Losa con escena de autosacrificio. Procede de Huilocintla, Veracruz. Museo Nacional de Antropología, México. Foto: Beatriz de la Fuente. 


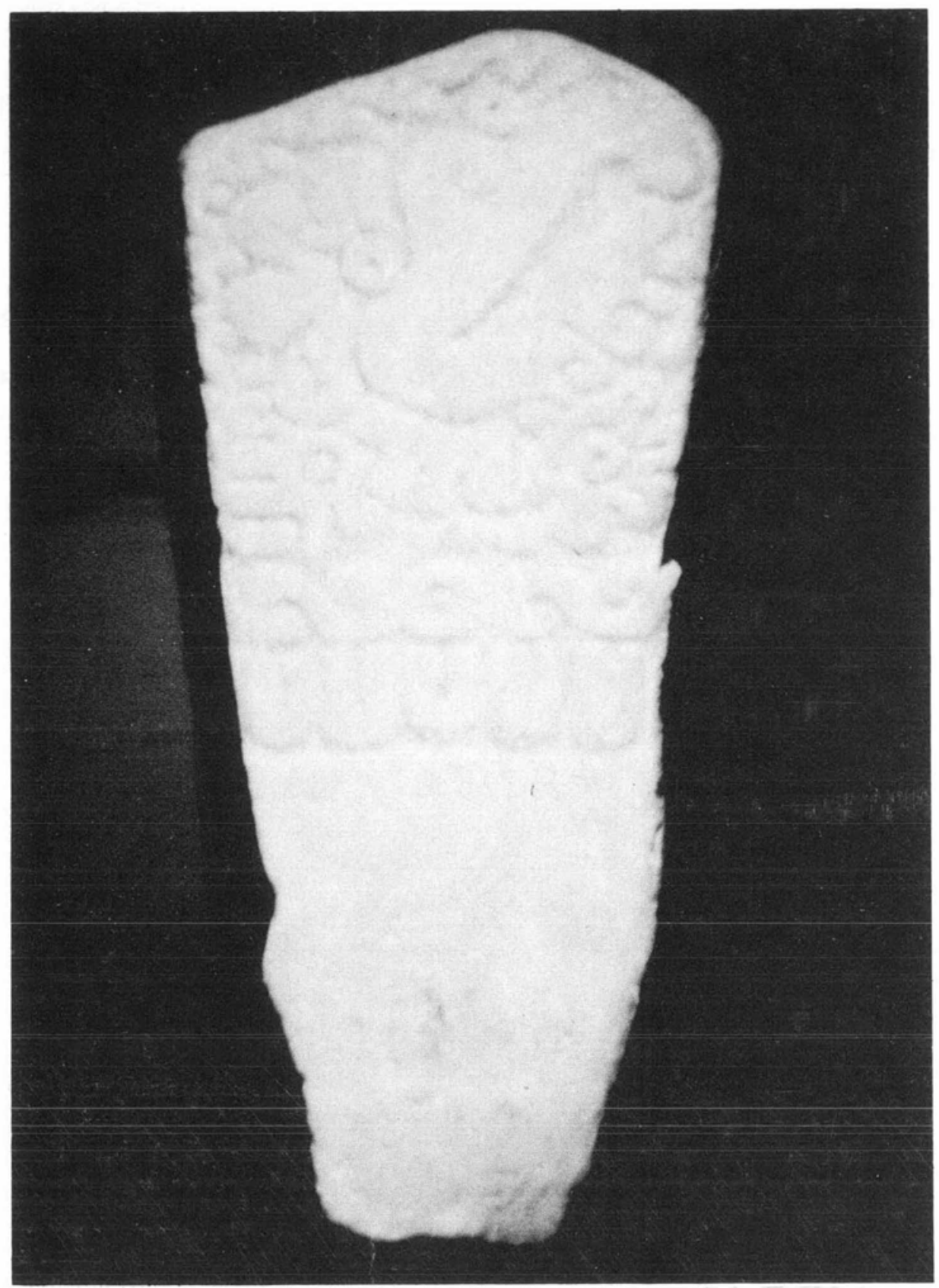

Lámina 26. Losa con la representación en relieve de un ave. The American Museum of Natural History, Nueva York. Foto: Silvia Trejo. 
1976 La Huasteca Los Señorías y Estados .Militaristas, SEP, INAH, Colec México: panorama histórico y cultural, pp. 243-290, México

\section{MAC NEISH, Richards}

1947 A Preliminary Report on Coastal Tamaulipas, México Ameruan intiquity, Vol XIII, Núm 1, pp 1-15, Society for American Archaeology, Menasha.

1954 An Early Archacological Site Near Pánuco, Veracruz

Transatlions of the Philosuphicat Saciety Vol XLIV, part 5, Philadelphia

\section{MEADE, Joaquin}

1939 Exploraciones en la Huaxteca Potosina l'igésimo Séptimo Congress Internaconal de Americamstas, Vol 2, pp. 13-24. INAH, México

1942 La Huasteca, Epoca Antigua. Publicaciones Históricas, México

1946 cría de San Lums Potosí. Talleres Gráficos, México.

1948 trquenlogin de San L.m, Polmi, Ediciones de la Sociedad de Geografia y Estadística, México.

1951 La Ihatera Ouertema. Monografias Huastecas V y VI Imprenta Aldina, México

1951 Ia Luastera Poblana Academia Mexicana de la Historia, Memorias, Vol 10, Núm 3, pp. 313-348, México

1953 Historia Prehispánica de la Huasteca Hutastecos, Totonaces y sus zecones, $R$ U E A, Vol XIII, pp. 291-302, México

1062 La Huasteca I eramizana Vol I, Ed Citlaltépetl, Veracruz

MEDELLÍN ZENIL, Alfonso

1955 Investigaciones en la Región de Chicontepec, Ver Buletín Bibliográfico de Antropología Americama, Vol XVIII, pp 134-137, Instituto Panamericano de Geografía e Historia

PIÑ A CHÃN, Román.

1967 lan lision del léven Prehidänuco, I. I H UNAM, México

\section{RODRÍGUEZ, Blas}

1932 Tempres, Datos para la Histona de la Htasteca. Ed Cultura, México.

1939 Una Escultura Huasteca Vigésimoséptimo Congreso International de Americanistas. Tomo I, pp. 587-600, Instituto Nacional de Antropologia e Historia, México

1943 (ulleras Hhaveray Olmea Editora Intercontinental, México

\section{SELER, Eduard}

1902-23a Die Monumenten Von Huilocintla im Canton Tuxpan, Des States Veracruz In Gi-

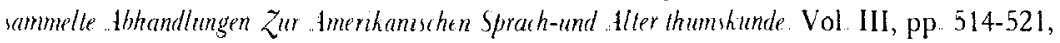
Berlin.

1902-23b Mexicaniscbe Skulpturen in Totonakengebiete G'sammelte Abhandlungen, zur Amerhamushen Sprach-lend dller thumskunde Vol. III, pp. 543-544, Berlin 
1904a Las Antiguas Coloniás en la Región de la Huasteca. Colectión de Disertaciones sobre Filologia y Arqueología Americana. MS Archivo de la Biblioteca del Museo de Antropología. Tomo Segundo, pp 148-166, México

1904b Esculturas Mexicanas en Territorio Totonaca. Colección de Disettaciones sabre Filologia y Arqueología Americana. MS. Archivo de la Biblioteca del Museo de Antropologia Tomo octavo, pp. 168-169, México.

STAUB, Walter

1919 Some Data about the Pre-hispanic and the now living Huastec Indians. El México Antiguo. Tomo I, No 3, pp. 1-65, México

1926 Le Nord-Est du Mexique et les Indiens de la Huaxtéque. In Journal de la Societé des Américanistes, N.S., Vol. XVIII, pp. 279-296, Paris.

STRESSER-PÉAN, Guy

1967 Recherches Francaises au Mexique et en Amérique Centrale, 1962-1968. Journal de la Societé des Américanistes, 'Tomo LVI-2, pp. 583-610, Musée de L'Homme, Paris

1971 Ancient Sources on The Huasteca. Handbook of Middle American Indians, Vol, II, pp. 582602. University of Texas. Press, Austin.

TREJO CAMPOS, Silvia

1978 Estilo Escultónico del Río Tamuín. Figuras Masculinas. Tesis de Licenciatura Universidad Iberoamericana, México

VELÁZQUEZ, Primo F

1946 Historia de San Luis Potosí. Vol I, Sociedad Mexicana de Geografia y Estadística, México 